\title{
Vitamin D from Supplements Consumed during Infancy and Toddlerhood and Bone Health: A Systematic Review
}

2020 Dietary Guidelines Advisory Committee, Birth to 24 Months Subcommittee

Published date: July 15, 2020

Nutrition Evidence Systematic Review

Center for Nutrition Policy and Promotion

Food and Nutrition Service

U.S. Department of Agriculture

Braddock Metro Center II

1320 Braddock Place

Alexandria, Virginia 22314 
This systematic review was conducted by the 2020 Dietary Guidelines Advisory Committee in collaboration with the Nutrition Evidence Systematic Review (NESR) team at the Center for Nutrition Policy and Promotion, Food and Nutrition Service, U.S. Department of Agriculture (USDA). All systematic reviews from the 2020 Advisory Committee Project are available on the NESR website: https://nesr.usda.gov/2020-dietary-guidelines-advisory-committeesystematic-reviews.

Conclusion statements drawn as part of this systematic review describe the state of science related to the specific question examined. Conclusion statements do not draw implications, and should not be interpreted as dietary guidance. This portfolio provides the complete documentation for this systematic review. A summary of this review is included in the 2020 Advisory Committee's Scientific Report available at www.DietaryGuidelines.gov.

The contents of this document may be used and reprinted without permission. Endorsements by NESR, the Center for Nutrition Policy and Promotion, the Food and Nutrition Service, or the USDA of derivative products developed from this work may not be stated or implied.

Suggested citation for this systematic review: 2020 Dietary Guidelines Advisory Committee and Nutrition Evidence Systematic Review Team. Vitamin D from Supplements Consumed during Infancy and Toddlerhood and Bone Health: A Systematic Review. 2020 Dietary Guidelines Advisory Committee Project. Alexandria, VA: U.S. Department of Agriculture, Food and Nutrition Service, Center for Nutrition Policy and Promotion, July 2020. Available at: https://nesr.usda.gov/2020-dietary-guidelines-advisory-committee-systematic-reviews.

Related citation: Dietary Guidelines Advisory Committee. 2020. Scientific Report of the 2020 Dietary Guidelines Advisory Committee: Advisory Report to the Secretary of Agriculture and the Secretary of Health and Human Services. U.S. Department of Agriculture, Agricultural Research Service, Washington, DC.

In accordance with Federal civil rights law and USDA civil rights regulations and policies, the USDA, its Agencies, offices, and employees, and institutions participating in or administering USDA programs are prohibited from discriminating based on race, color, national origin, religion, sex, gender identity (including gender expression), sexual orientation, disability, age, marital status, family/parental status, income derived from a public assistance program, political beliefs, or reprisal or retaliation for prior civil rights activity, in any program or activity conducted or funded by USDA (not all bases apply to all programs). Remedies and complaint filing deadlines vary by program or incident.

Persons with disabilities who require alternative means of communication for program information (e.g., Braille, large print, audiotape, American Sign Language, etc.) should contact the responsible Agency or USDA's TARGET Center at (202) 720-2600 (voice and TTY) or contact USDA through the Federal Relay Service at (800) 877-8339. Additionally, program information may be made available in languages other than English.

To file a program discrimination complaint, complete the USDA Program Discrimination Complaint Form, AD-3027, found online at How to File a Program Discrimination Complaint and at any USDA office or write a letter addressed to USDA and provide in the letter all of the information requested in the form. To request a copy of the complaint form, call (866) 632-9992. Submit your completed form or letter to USDA by: (1) mail: U.S. Department of Agriculture, Office of the Assistant Secretary for Civil Rights, 1400 Independence Avenue, SW, Washington, D.C. 20250-9410; (2) fax: (202) 690-7442; or (3) email: program.intake@usda.gov.

USDA is an equal opportunity provider, employer, and lender. 


\section{Birth to 24 Months Subcommittee:}

- Kathryn Dewey, PhD, University of California, Davis, Subcommittee Chair

- Lydia Bazzano, MD, PhD, Tulane University and Ochsner Health System

- Teresa Davis, PhD, Baylor College of Medicine

- Sharon Donovan, $\mathrm{PhD}, \mathrm{RD}$, University of Illinois, Urbana-Champaign

- Elsie Taveras, MD, MPH, Massachusetts General Hospital, Harvard Medical School, and Harvard T.H. Chan School of Public Health

- Ronald Kleinman, MD, Massachusetts General Hospital and Harvard Medical School, Vice-Chair of the 2020 Dietary Guidelines Advisory Committee

\section{Nutrition Evidence Systematic Review (NESR) Team:}

- Darcy Güngör, MS, Analyst, Panum Group ${ }^{i}$

- Sudha Venkatramanan, PhD, Analyst, Panum Groupi

- Emily Madan, PhD, Analyst, Panum Groupi

- Laural Kelly English, PhD, MS, Analyst, Panum Groupi

- Nancy Terry, MS, MLS, Biomedical Librarian, National Institutes of Health (NIH), U.S. Department of Health and Human Services (HHS)

- Gisela Butera, MLIS, MEd, Systematic Review Librarian, Panum Group ${ }^{i}$

- Julie Obbagy, PhD, RD, Project Lead, Office of Nutrition Guidance and Analysis (ONGA), Center for Nutrition Policy and Promotion (CNPP), Food and Nutrition Service (FNS), U.S. Department of Agriculture (USDA)

\section{Federal Liaisons:}

- Cria Perrine, PhD, Division of Nutrition, Physical Activity, and Obesity, Centers for Disease Control and Prevention, HHS

- Jennifer Lerman, MPH, RD, National Cancer Institute, NIH, HHS

- Kelley Scanlon, PhD, RD, Special Nutrition Research and Analysis Division, Office of Policy Support, FNS, USDA

\section{Project Leadership:}

- Eve Essery Stoody, PhD, Designated Federal Officer and Director, ONGA, CNPP, FNS, USDA

- Janet de Jesus, MS, RD, Nutrition Advisor, Office of Disease Prevention and Health Promotion, Office of the Assistant Secretary for Health, HHS

USDA and HHS implemented a process to identify topics and scientific questions to be examined by the 2020 Dietary Guidelines Advisory Committee. The Committee conducted its review of evidence in subcommittees for discussion by the full Committee during its public meetings. The role of the Committee members involved establishing all aspects of the protocol, which presented

\footnotetext{
i Under contract with the Food and Nutrition Service, United States Department of Agriculture.
} 
the plan for how they would examine the scientific evidence, including the inclusion and exclusion criteria; reviewing all studies that met the criteria they set; deliberating on the body of evidence for each question; and writing and grading the conclusion statements to be included in the scientific report the 2020 Committee submitted to USDA and HHS. The NESR team with assistance from Federal Liaisons and Project Leadership, supported the Committee by facilitating, executing, and documenting the work necessary to ensure the reviews were completed in accordance with NESR methodology. More information about the 2020 Dietary Guidelines Advisory Committee, including the process used to identify topics and questions, can be found at www. DietaryGuidelines.gov. More information about NESR can be found at NESR.usda.gov.

The Committee and NESR staff thank USDA's Agricultural Research Service for coordinating the peer review of this systematic review, and the Federal scientist peer reviewers for their time and expertise.

FUNDING SOURCE: United States Department of Agriculture, Food and Nutrition Service, Center for Nutrition Policy and Promotion, Alexandria, VA 


\section{TABLE OF CONTENTS}

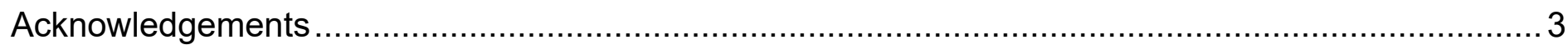

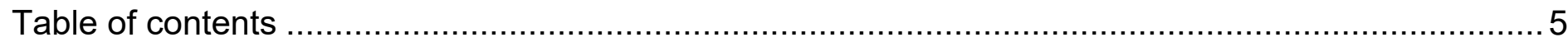

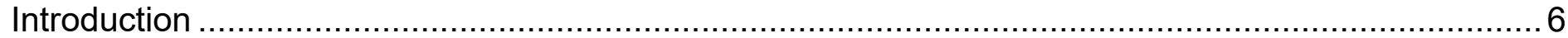

What is the relationship between vitamin $D$ from supplements consumed during infancy and

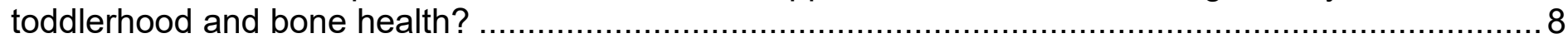

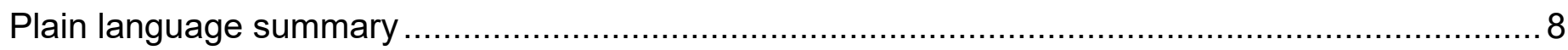

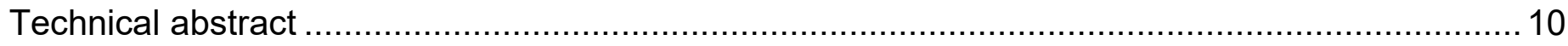

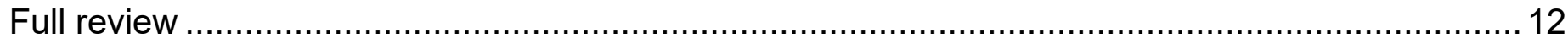

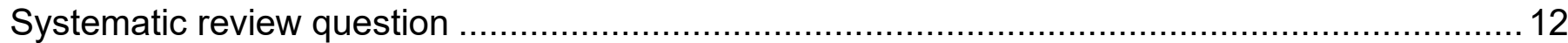

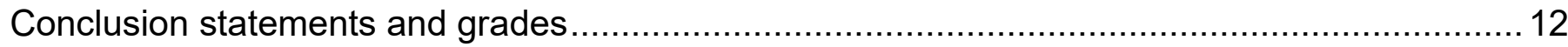

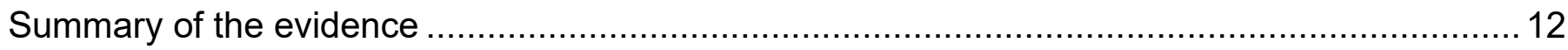

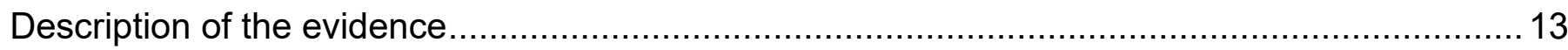

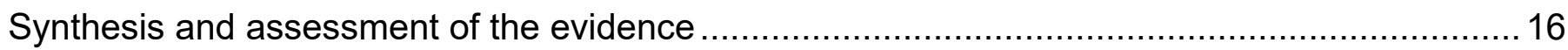

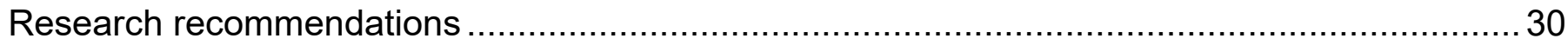

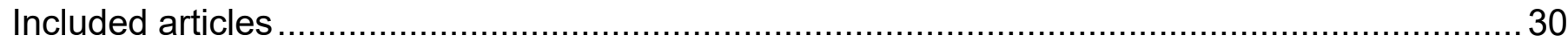

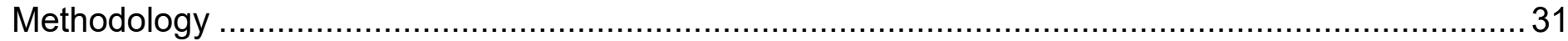

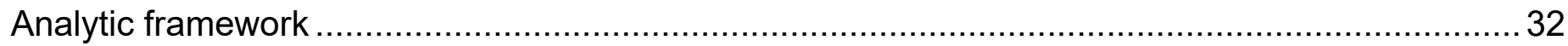

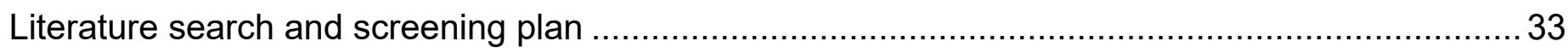

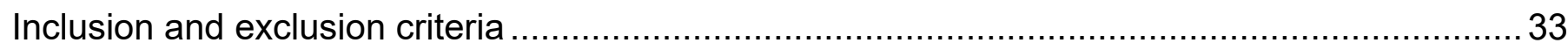

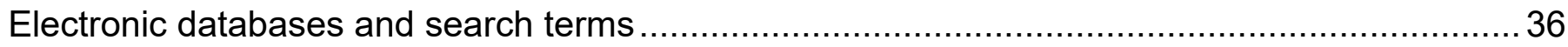

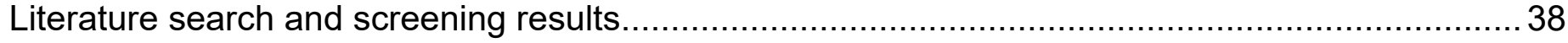

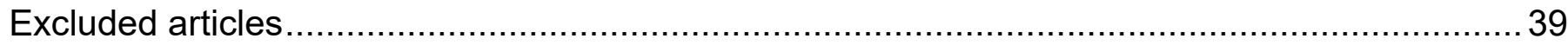

Table 1. Infant feeding and dietary and environmental sources of vitamin D ................................. 14

Table 2. Evidence examining the relationship between vitamin $D$ from supplements consumed during infancy and toddlerhood and bone health

Table 3. Risk of bias for randomized controlled trials examining consumption of vitamin D from

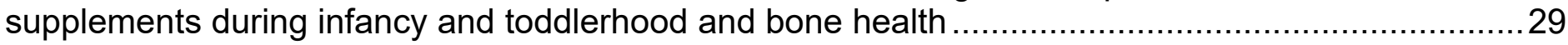

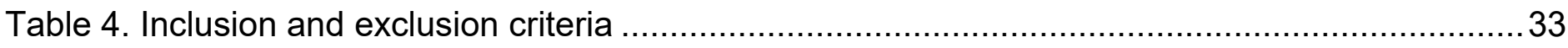

Table 5. Articles excluded after full text screening with rationale for exclusion ..................................39

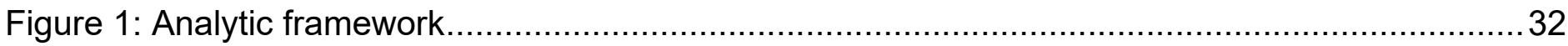

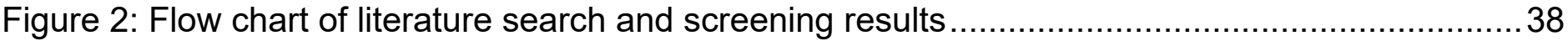




\section{INTRODUCTION}

This document describes a systematic review conducted to answer the following question: What is the relationship between vitamin $D$ from supplements consumed during infancy and toddlerhood and bone health? This systematic review was conducted by the 2020 Dietary Guidelines Advisory Committee, supported by USDA's Nutrition Evidence Systematic Review (NESR).

More information about the 2020 Dietary Guidelines Advisory Committee is available at the following website: www.DietaryGuidelines.gov.

NESR specializes in conducting food- and nutrition-related systematic reviews using a rigorous, protocol-driven methodology. More information about NESR is available at the following website: NESR.usda.gov.

NESR's systematic review methodology involves developing a protocol, searching for and selecting studies, extracting data from and assessing the risk of bias of each included study, synthesizing the evidence, developing conclusion statements, grading the evidence underlying the conclusion statements, and recommending future research. A detailed description of the systematic reviews conducted for the 2020 Dietary Guidelines Advisory Committee, including information about methodology, is available on the NESR website: https://nesr.usda.gov/2020-dietary-guidelinesadvisory-committee-systematic-reviews. In addition, starting on page 31, this document describes the final protocol as it was applied in the systematic review. A description of and rationale for modifications made to the protocol are described in the 2020 Dietary Guidelines Advisory Committee Report, Part D: Chapter 6. Nutrients from Dietary Supplements During Infancy and Toddlerhood. 
List of abbreviations

\begin{tabular}{ll} 
Abbreviation & Full name \\
\hline 25(OH)D & 25-Hydroxy Vitamin D \\
\hline Al & Adequate Intake \\
\hline ALP & Alkaline Phosphatase \\
\hline BMC & Bone Mineral Content \\
\hline BMD & Bone Mineral Density \\
\hline CNPP & Center for Nutrition Policy and Promotion \\
\hline CTX & C-Terminal Telopeptides \\
\hline FNS & USDA Food and Nutrition Service \\
\hline HHS & U.S. Department of Health and Human Services \\
\hline IU & International Units \\
\hline NESR & Nutrition Evidence Systematic Review \\
\hline NIH & National Institutes of Health \\
\hline ONGA & Office of Nutrition Guidance and Analysis \\
\hline PINP & Procollagen I N-Terminal Propeptide \\
\hline RDA & Recommended Dietary Allowance \\
\hline USDA & U.S. Department of Agriculture \\
\hline
\end{tabular}




\section{PLAIN LANGUAGE SUMMARY}

\section{What is the question?}

- The question is: What is the relationship between vitamin $D$ from supplements consumed during infancy and toddlerhood and bone health?

What is the answer to the question?

- Limited evidence suggests no relationship between consumption of 400 IU per day of vitamin D from supplements before age 12 months, compared with higher dosages of up to $1600 \mathrm{IU}$ per day, and biomarkers of bone metabolism in children up to age 36 months.

- Insufficient evidence is available to determine the relationship between $400 \mathrm{IU}$ per day of vitamin D from supplements, compared with higher dosages, and bone mass, rickets, or fracture.

- Insufficient evidence is available to determine the relationship between $400 \mathrm{IU}$ per day of vitamin D from supplements, compared with lower dosages, and bone mass, biomarkers of bone metabolism, rickets, or fracture.

- Insufficient evidence is available to determine the relationship between vitamin $D$ from supplements, compared with no vitamin D from supplements, and bone mass, biomarkers of bone metabolism, rickets, or fracture.

- Insufficient evidence is available to determine the relationship between vitamin $D$ from supplements, compared with vitamin D from fortified foods, and bone mass, biomarkers of bone metabolism, rickets, or fracture.

\section{Why was this question asked?}

- This important public health question was identified by the U.S. Departments of Agriculture (USDA) and Health and Human Services (HHS) to be examined by the 2020 Dietary Guidelines Advisory Committee.

\section{How was this question answered?}

- The 2020 Dietary Guidelines Advisory Committee, Birth to 24 Months Subcommittee, conducted a systematic review to answer this question with support from the Nutrition Evidence Systematic Review (NESR) team.

\section{What is the population of interest?}

- Vitamin D supplementation was examined in healthy infants and toddlers (birth to 24 months) with outcomes measured at birth through age 18 years.

\section{What evidence was found?}

- This review includes 6 articles. 
- The articles compared infants and toddlers who consumed different dosages of vitamin $D$ from supplements. Most articles compared infants supplemented with 400 International Units (IU) per day (which is the Adequate Intake for infants) with infants supplemented with higher dosages.

- The outcomes of interest were bone mass, biomarkers of bone metabolism, rickets, and fracture from birth to age 18 years. Most articles examined bone mass and biomarkers of bone metabolism in children up to age 36 months.

- Limited evidence suggests that infants who are supplemented with $400 \mathrm{IU}$ per day and infants who are supplemented with higher dosages of up to $1600 \mathrm{IU}$ per day do not have differences in biomarkers of bone metabolism up to age 36 months, but the evidence related to bone mass was inconsistent.

- There are limitations in the evidence as follows:

- There were not a lot of articles, and some of the articles studied groups of infants and toddlers that may have been too small to detect a relationship between iron supplementation and growth or size.

- The studies examined infants who were given supplements for different lengths of time, examined different biomarkers of bone metabolism, and measured the biomarkers at different ages, so comparing the findings of the studies was difficult.

- In the studies that reported race, most or all infants were white. The findings may or may not be the same in other racial or ethnic groups.

\section{How up-to-date is this systematic review?}

- This review searched for studies from January, 2000 to January, 2020 


\section{TECHNICAL ABSTRACT}

\section{Background}

- This important public health question was identified by the U.S. Departments of Agriculture (USDA) and Health and Human Services (HHS) to be examined by the 2020 Dietary Guidelines Advisory Committee.

- The 2020 Dietary Guidelines Advisory Committee, Birth to 24 Months Subcommittee conducted a systematic review to answer this question with support from the Nutrition Evidence Systematic Review (NESR) team.

- The goal of this systematic review was to examine the following question: What is the relationship between vitamin $\mathrm{D}$ from supplements consumed during infancy and toddlerhood and bone health?

\section{Conclusion statements and grades}

- Limited evidence suggests no relationship between consumption of $400 \mathrm{IU}$ per day of vitamin $\mathrm{D}$ from supplements before age 12 months, compared with higher dosages of up to $1600 \mathrm{IU}$ per day, and biomarkers of bone metabolism in children up to age 36 months. (Grade: Limited)

- Insufficient evidence is available to determine the relationship between $400 \mathrm{IU}$ per day of vitamin $\mathrm{D}$ from supplements, compared with higher dosages, and bone mass, rickets, or fracture. (Grade: Grade not assignable)

- Insufficient evidence is available to determine the relationship between $400 \mathrm{IU}$ per day of vitamin $\mathrm{D}$ from supplements, compared with lower dosages, and bone mass, biomarkers of bone metabolism, rickets, or fracture. (Grade: Grade not assignable)

- Insufficient evidence is available to determine the relationship between vitamin $D$ from supplements, compared with no vitamin $D$ from supplements, and bone mass, biomarkers of bone metabolism, rickets, or fracture. (Grade: Grade not assignable)

- Insufficient evidence is available to determine the relationship between vitamin $D$ from supplements, compared with vitamin D from fortified foods, and bone mass, biomarkers of bone metabolism, rickets, or fracture. (Grade: Grade not assignable)

\section{Methods}

- A literature search was conducted using 4 databases (PubMed, Cochrane, Embase, and CINAHL) to identify articles that evaluated the intervention or exposure of vitamin $D$ from supplements consumed during infancy and toddlerhood and bone health outcomes. A manual search was conducted to identify articles that may not have been included in the electronic databases searched. Articles were screened by two NESR analysts independently for inclusion based on pre-determined criteria.

- Data extraction and risk of bias assessment were conducted for each included study, and both were checked for accuracy. The Committee qualitatively synthesized the body of evidence to inform development of conclusion statements, and graded the strength of evidence using preestablished criteria for risk of bias, consistency, directness, precision, and generalizability. 


\section{Summary of the evidence}

- Six articles met the inclusion criteria for this systematic review, which presented evidence from 5 independent randomized controlled trials (1 research group published 2 articles about the same trial).

- The intervention of interest was vitamin D from supplements consumed during infancy or toddlerhood. Dietary supplements are products that contain one or more dietary ingredients (in this case, vitamin D) intended to be taken by mouth to supplement the diet. In the United States, $400 \mathrm{IU}$ of vitamin D per day is the Al for infants younger than age 12 months, whereas the RDA for ages 12 to 24 months of age is $600 \mathrm{IU}$ per day. To meet this need, the American Academy of Pediatrics currently recommends a supplement of $400 \mathrm{IU}$ per day for infants fed human milk (with the possible exception of infants whose mothers are taking supplements of about 6000 IU per day; maternal vitamin D supplementation during lactation was outside of the scope of this systematic review).

- The comparators of interest were different dosages of vitamin D from supplements and vitamin $D$ from fortified foods. However, no articles were identified that included fortified food comparators.

- The outcomes of interest were bone mass, biomarkers of bone metabolism, rickets, and fracture through adolescence (i.e., birth through age 18 years). However, no articles were identified that examined fracture or outcomes beyond age 36 months.

- Limited evidence from 3 studies suggests no relationship between 400 IU per day of vitamin D from supplements, compared with higher dosages, and biomarkers of bone metabolism in children up to age 36 months. The ability to draw a stronger conclusion was primarily limited by a small number of studies, small sample sizes, heterogeneous methods, and limited generalizability.

- Evidence available from 4 studies was insufficient to determine whether a relationship exists between 400 IU per day of vitamin D from supplements, compared with higher dosages, and bone mass. The ability to draw a conclusion was hindered by inconsistent findings from a small number of studies. No studies were available that examined the relationship between $400 \mathrm{IU}$ per day of vitamin D from supplements, compared with higher dosages, and rickets or bone fracture.

- Evidence available from 1 study was insufficient to determine whether a relationship exists between $400 \mathrm{IU}$ per day of vitamin D from supplements, compared with lower dosages, and bone mass or biomarkers of bone metabolism. No studies were available that examined the relationship between 400 IU per day of vitamin D from supplements, compared with lower dosages, and rickets or fracture.

- Evidence available from 1 study was insufficient to determine whether a relationship exists between 200 IU per day of vitamin D from supplements for different durations, compared with no vitamin $D$ from supplements, and biomarkers of bone metabolism or rickets. No studies were available that examined the relationship between $200 \mathrm{IU}$ per day of vitamin D from supplements for different durations, compared with no vitamin D from supplements, and bone mass or fracture. No studies were available that compared other dosages of vitamin $D$ from supplements with no supplementation. It is likely that the evidence that led to the current supplementation recommendation pre-dates our literature search date range of January 2000 to January 2020. 


\section{FULL REVIEW}

\section{Systematic review question}

What is the relationship between vitamin $D$ from supplements consumed during infancy and toddlerhood and bone health?

\section{Conclusion statements and grades}

Limited evidence suggests no relationship between consumption of $400 \mathrm{IU}$ per day of vitamin D from supplements before age 12 months, compared with higher dosages of up to $1600 \mathrm{IU}$ per day, and biomarkers of bone metabolism in children up to age 36 months. (Grade: Limited)

Insufficient evidence is available to determine the relationship between $400 \mathrm{IU}$ per day of vitamin $\mathrm{D}$ from supplements, compared with higher dosages, and bone mass, rickets, or fracture. (Grade: Grade not assignable)

Insufficient evidence is available to determine the relationship between $400 \mathrm{IU}$ per day of vitamin $\mathrm{D}$ from supplements, compared with lower dosages, and bone mass, biomarkers of bone metabolism, rickets, or fracture. (Grade: Grade not assignable)

Insufficient evidence is available to determine the relationship between vitamin $D$ from supplements, compared with no vitamin $D$ from supplements, and bone mass, biomarkers of bone metabolism, rickets, or fracture. (Grade: Grade not assignable)

Insufficient evidence is available to determine the relationship between vitamin $D$ from supplements, compared with vitamin $\mathrm{D}$ from fortified foods, and bone mass, biomarkers of bone metabolism, rickets, or fracture. (Grade: Grade not assignable)

\section{Summary of the evidence}

- Six articles met the inclusion criteria for this systematic review, ${ }^{1-6}$ which presented evidence from 5 independent randomized controlled trials ( 1 research group published 2 articles about the same trial).

- The intervention of interest was vitamin D from supplements consumed during infancy or toddlerhood. Dietary supplements are products that contain one or more dietary ingredients (in this case, vitamin D) intended to be taken by mouth to supplement the diet. ${ }^{\text {ii }}$ In the United States, $400 \mathrm{IU}$ of vitamin D per day is the Al for infants younger than age 12 months, whereas the RDA for ages 12 to 24 months of age is $600 \mathrm{IU}$ per day. To meet this need, the American Academy of Pediatrics currently recommends a supplement of $400 \mathrm{IU}$ per day for infants fed human milk (with the possible exception of infants whose mothers are taking supplements of about 6000 IU per day iii; maternal vitamin D supplementation during lactation was outside of the scope of this systematic review).

- The comparators of interest were different dosages of vitamin $D$ from supplements and

\footnotetext{
ii National Institutes of Health Office of Dietary Supplements. Dietary Supplement Health and Education Act of 1994 Public Law 103-417 103rd Congress: Sec. 3. Definitions. https://ods.od.nih.gov/About/DSHEA Wording.aspx\#sec3 Published October 25, 1994. Accessed May 18, 2020

iii Golden NH, Abrams SA. Optimizing bone health in children and adolescents. Pediatrics. 2014;134(4):e1229-1243. doi:10.1542/peds.2014-2173.
} 
vitamin $\mathrm{D}$ from fortified foods. However, no articles were identified that included fortified food comparators.

- The outcomes of interest were bone mass, biomarkers of bone metabolism, rickets, and fracture through adolescence (i.e., birth through age 18 years), However, no articles were identified that examined fracture or outcomes beyond 36 months.

- Limited evidence from 3 studies suggests no relationship between $400 \mathrm{IU}$ per day of vitamin $\mathrm{D}$ from supplements, compared with higher dosages, and biomarkers of bone metabolism in children up to age 36 months. The ability to draw a stronger conclusion was primarily limited by a small number of studies, small sample sizes, heterogeneous methods, and limited generalizability.

- Evidence available from 4 studies was insufficient to determine whether a relationship exists between 400 IU per day of vitamin D from supplements, compared with higher dosages, and bone mass. The ability to draw a conclusion was hindered by inconsistent findings from a small number of studies. No studies were available that examined the relationship between $400 \mathrm{IU}$ per day of vitamin D from supplements, compared with higher dosages, and rickets or bone fracture.

- Evidence available from 1 study was insufficient to determine whether a relationship exists between 400 IU per day of vitamin D from supplements, compared with lower dosages, and bone mass or biomarkers of bone metabolism. No studies were available that examined the relationship between $400 \mathrm{IU}$ per day of vitamin D from supplements, compared with lower dosages, and rickets or fracture.

- Evidence available from 1 study was insufficient to determine whether a relationship exists between 200 IU per day of vitamin D from supplements for different durations, compared with no vitamin $D$ from supplements, and biomarkers of bone metabolism or rickets. No studies were available that examined the relationship between $200 \mathrm{IU}$ per day of vitamin D from supplements for different durations, compared with no vitamin $D$ from supplements, and bone mass or fracture. No studies were available that compared other dosages of vitamin $\mathrm{D}$ from supplements with no supplementation. It is likely that the evidence that led to the current supplementation recommendation pre-dates our literature search date range of January 2000 to January 2020.

\section{Description of the evidence}

This systematic review examines available evidence about the relationship between vitamin $D$ from supplements consumed during infancy and toddlerhood and bone health from birth through adolescence.

Six articles, published between 2010 and 2018, met the inclusion criteria. ${ }^{1-6}$ The 6 articles present evidence from 5 independent randomized controlled trials; the 2 articles by Gallo et al ${ }^{1,2}$ are from the same study.

\section{Population}

Study participants were from the United States, ${ }^{4,6}$ Canada, ${ }^{1,2}$ and Finland. ${ }^{3,5}$ In 3 studies, the participants were predominantly or entirely White,,$^{1,2,5,6}$ and the remaining 2 studies did not report race or ethnicity. ${ }^{3,4}$

Baseline vitamin D status was similar in 3 studies, with serum 25-hydroxy vitamin $D[25(\mathrm{OH}) \mathrm{D}]$ averaging $50-56 \mathrm{nmol} / \mathrm{L} .{ }^{1-4}$ Rosendahl et al ${ }^{5}$ reported that for the majority of infants $(52 \%)$, the 

concentrations.

The studies focused on infants fed human milk. Intake of infant formula, dietary sources of vitamin D, and sun exposure varied between studies (Table 1).

\section{Table 1. Infant feeding and dietary and environmental sources of vitamin D}

\begin{tabular}{|c|c|c|c|}
\hline Study & Human milk and infant formula & Dietary vitamin D & Sun exposure \\
\hline Gallo et al ${ }^{1,2}$ & $\begin{array}{l}\text { - Recruited infants }<1 \text { month } \\
\text { consuming } \geq 80 \% \text { total milk } \\
\text { volume as human milk; } 88 \% \text { and } \\
35 \% \text { consumed any human milk at } \\
6 \text { and } 12 \text { months, respectively } \\
\text { Average formula intake increased } \\
\text { from } 35 \mathrm{~g} / \mathrm{d} \text { at } 1 \text { month to } 155 \mathrm{~g} / \mathrm{d} \\
\text { at } 6 \text { months and } 252 \mathrm{~g} / \mathrm{d} \text { by } 12 \\
\text { months }\end{array}$ & $\begin{array}{l}\text { - Average dietary } \\
\text { intake of vitamin } \\
D \text { increased from } \\
43 \mathrm{IU} / \mathrm{d} \text { at } 1 \\
\text { month to } 84 \mathrm{IU} / \mathrm{d} \\
\text { at } 6 \mathrm{months} \text { and } \\
245 \mathrm{IU} / \mathrm{d} \text { by } 12 \\
\text { months } \\
\text { Average dietary } \\
\text { intake of vitamin } \\
\text { D was } 247-302 \\
\text { IU/d at } 36 \\
\text { months, } \\
\text { depending on the } \\
\text { group }\end{array}$ & $\begin{array}{l}\text { - Average sun exposure (estimated } \\
\text { as h/wk * \% exposed body surface } \\
\text { area) increased from } 7 \text { at } 1 \text { month } \\
\text { to a peak of } 71 \text { at } 9 \text { months and } \\
\text { then decreased to } 56 \text { at } 12 \text { months; } \\
\text { at } 36 \text { months it was } 1.6-1.7 \\
\text { depending on the group } \\
\text { - About half (56\%) of infants were } \\
\text { born during the "synthesizing } \\
\text { period" of April to October when } \\
\text { cutaneous vitamin D production is } \\
\text { possible based on latitude } \\
\text { The majority of children (84-96\% } \\
\text { depending on the group) had fair or } \\
\text { very fair skin color }\end{array}$ \\
\hline $\begin{array}{l}\text { Holmlund- } \\
\text { Suila et } \mathrm{al}^{3}\end{array}$ & $\begin{array}{l}\text { - Infant feeding at recruitment not } \\
\text { reported } \\
\text { - At the time of the outcome } \\
\text { measure ( } 3 \text { months), } 95 \% \text { of } \\
\text { infants were consuming human } \\
\text { milk } \\
\text { - At the time of the outcome } \\
\text { measure (3 months) mean } \\
\text { formula intake was } 2.5 \mathrm{~L} / \mathrm{wk}\end{array}$ & $\begin{array}{l}\text { Not reported; } \\
\text { however, infants } \\
\text { were only } 3 \\
\text { months old by } \\
\text { the end of the } \\
\text { study }\end{array}$ & $\begin{array}{l}\text { - Not reported; however infants were } \\
\text { born in September to February in } \\
\text { Finland and followed for } 3 \text { months }\end{array}$ \\
\hline $\begin{array}{l}\text { Rosendahl et } \\
\text { al }^{5}\end{array}$ & $\begin{array}{l}\text { - The majority }(79 \%) \text { of infants were } \\
\text { fed human milk }>6 \text { months } \\
\text { - Formula intake was not reported }\end{array}$ & $\begin{array}{l}\text { Average dietary } \\
\text { intake of vitamin } \\
\text { D was } 248 \mathrm{IU} / \mathrm{d} \\
\text { at } 12 \text { months, } \\
\text { and not reported } \\
\text { at other ages }\end{array}$ & $\begin{array}{l}\text { - Not reported; however, authors } \\
\text { describe the population as } \\
\text { "northern European with limited } \\
\text { sunlight exposure" } \\
\text { - All infants were of northern } \\
\text { European ethnicity }\end{array}$ \\
\hline Ziegler et al $^{6}$ & $\begin{array}{l}\text { - } \quad \text { Recruited infants }<28 \text { days fed } \\
\text { human milk exclusively } \\
\text { - Caregivers encouraged not to } \\
\text { introduce infant formula until }>9 \\
\text { months }\end{array}$ & - $\quad$ Not reported & $\begin{array}{l}\text { - All infants Caucasian } \\
\text { - Outcomes measured at the end of } \\
\text { winter }\end{array}$ \\
\hline
\end{tabular}




\section{Interventions and comparators}

The intervention was vitamin $D$ from supplements consumed during infancy and toddlerhood. In all 5 studies, vitamin D was provided in the form of vitamin D3 drops.

Four studies compared $400 \mathrm{IU} / \mathrm{d}$ of vitamin $\mathrm{D}$ with higher dosages:

1. Gallo et al ${ }^{1,2}$ compared dosages of $400,800,1200$, and $1600 \mathrm{IU} / \mathrm{d}$ from 1 to 12 months of age (i.e., nearly 1 year of supplementation)

2. Holmlund-Suila et al ${ }^{3}$ compared dosages of 400,1200 , and $1600 \mathrm{IU} / \mathrm{d}$ from 2 weeks to 3 months of age (i.e., 2.5 months of supplementation)

3. Rosendahl et al ${ }^{5}$ compared dosages of 400 and $1200 \mathrm{lU} / \mathrm{d}$ from 2 weeks to 24 months of age (i.e., nearly 2 years of supplementation)

4. Ziegler et $\mathrm{al}^{6}$ compared 400,600 , and $800 \mathrm{IU} / \mathrm{d}$ from 2 to 9 months (i.e., 7 months of supplementation)

One study compared $400 \mathrm{IU} / \mathrm{d}$ with a lower dosage: Ziegler et al ${ }^{6}$ compared 400 and $200 \mathrm{IU} / \mathrm{d}$ from 2 to 9 months (i.e., 7 months of supplementation).

One study compared $200 \mathrm{IU} / \mathrm{d}$ for different durations with a placebo: Ponnapakkam et al ${ }^{4}$ compared $200 \mathrm{IU} / \mathrm{d}$ from birth to 6 months (i.e., 6 months of supplementation), $200 \mathrm{lU} / \mathrm{d}$ from 2 to 6 months (i.e., 4 months of supplementation), and placebo from birth to 6 months.

\section{Outcomes}

Four studies assessed bone mass outcomes:

1. Gallo et al ${ }^{1,2}$ reported:

- Femur, lumbar spine, and whole-body bone mineral content (BMC) at 3, 6, 9, and 12 months, and change in femur, lumbar spine, and whole-body BMC from 1 to 3,3 to 6,6 to 9 , and 9 to 12 months

- Lumbar spine and whole-body BMC 36 months, change in lumbar spine and wholebody BMC from 12 to 36 and 1 to 36 months, and lumbar spine and whole-body bone mineral density (BMD) and BMD z-score at 36 months

2. Holmlund-Suila et al ${ }^{3}$ reported:

- Total and trabecular bone and cortical bone BMD and cross-sectional area at 3 months, and polar stress and strain index (an indicator of bone strength) at 3 months

3. Rosendahl et al ${ }^{5}$ reported:

- Total bone and cortical bone BMC, BMD, cross-sectional area, and polar moment of inertia at 24 months

4. Ziegler et al ${ }^{6}$ reported:

- Whole-body BMC and BMD at the end of winter (i.e., infant ages 5.5-9 months) and in subsamples of infants who were 5.5, 7.5, and 9 months at end of winter

Four studies assessed biomarkers of bone formation and bone resorption:

Bone formation biomarkers

- Alkaline phosphatase (ALP) at 2, 4, and 6 months $^{4}$ and 4, 5.5, 7.5, and 9 months ${ }^{6}$ 
- Osteocalcin at 4, 5.5, 7.5, and 9 months $^{6}$

- Procollagen I N-terminal propeptide (PINP) at 3 months $^{3}$

Bone resorption biomarkers

- C-terminal telopeptides (CTX) at 3 months ${ }^{3} ; 4,5.5,7.5$, and 9 months $^{6}$; and 36 months ${ }^{2}$

One study assessed rickets: Ponnapakkam et al ${ }^{4}$ reported the incidence of rickets at 2, 4, and 6 months.

\section{Synthesis and assessment ${ }^{\text {iv }}$ of the evidence}

\section{Comparisons of $400 \mathrm{IU} / \mathrm{d}$ with higher dosages of vitamin $\mathrm{D}$}

Four of the 5 studies compared $400 \mathrm{IU} / \mathrm{d}$ of vitamin $\mathrm{D}$ with higher dosages. ${ }^{1-3,5,6}$ The Adequate Intake (Al) for infants is $400 \mathrm{IU} / \mathrm{d}$ of vitamin $\mathrm{D}$ and the Recommended Dietary Allowance (RDA) for children ages 1 year and older is $600 \mathrm{lU} / \mathrm{d}$. $v$ To meet this need, the American Academy of Pediatrics currently recommends a supplement of $400 \mathrm{IU} / \mathrm{d}$ for human milk-fed infants (with the possible exception of infants whose mothers are taking supplements of about $6000 \mathrm{lU} / \mathrm{d}$ ). ${ }^{\mathrm{vi}}$

All 4 studies examined bone mass outcomes, and 3 examined biomarkers of bone metabolism.

\section{Bone Mass}

The evidence was inconsistent with regard to the statistical significance of the findings and the direction of the statistically significant relationships. These inconsistencies are outlined below.

Holmlund-Suila et $\mathrm{al}^{3}$ reported significant positive relationships and Ziegler et $\mathrm{al}^{6}$ reported significant inverse relationships between vitamin $\mathrm{D}$ dosage and bone mass in infants:

- Holmlund-Suila et al ${ }^{3}$ compared infants given 400, 1200, and $1600 \mathrm{IU} / \mathrm{d}$ of vitamin D3 from 2 weeks to 3 months of age. Infants given $1600 \mathrm{IU} / \mathrm{d}$ had: (a) significantly higher total and trabecular bone cross-sectional area at 3 months than infants given $400 \mathrm{IU} / \mathrm{d}$ (but not 1200 IU/d); (b) significantly higher cortical bone cross-sectional area at 3 months than infants given 400 or $1200 \mathrm{lU} / \mathrm{d}$; and (c) significantly higher polar stress and strain index at 3 months than infants given 400 or $1200 \mathrm{IU} / \mathrm{d}$. There were no significant differences in total and trabecular bone or cortical bone BMD at 3 months.

- Ziegler et al ${ }^{6}$ compared infants given 400,600, and $800 \mathrm{IU} / \mathrm{d}$ of vitamin D3 from 2 to 9 months of age. Infants given $600 \mathrm{IU} / \mathrm{d}$ had: (a) significantly lower whole-body BMC at the end of winter (i.e., 5.5-9 months) than infants given $400 \mathrm{lU} / \mathrm{d}$, and (b) significantly lower whole-body BMD at the end of winter than infants given $400 \mathrm{lU} / \mathrm{d}$. There were also no

\footnotetext{
iv A detailed description of the methodology used for grading the strength of the evidence is available on the NESR website: https://nesr.usda.gov/2020-dietary-guidelines-advisory-committee-systematic-reviews and in Part C of the following reference: Dietary Guidelines Advisory Committee. 2020. Scientific Report of the 2020 Dietary Guidelines Advisory Committee: Advisory Report to the Secretary of Agriculture and the Secretary of Health and Human Services. U.S. Department of Agriculture, Agricultural Research Service, Washington, DC.

${ }^{v}$ Institute of Medicine. Dietary Reference Intakes for Calcium and Vitamin D. Washington, DC: The National Academies Press;2011. doi:10.17226/13050. 978-0-309-16394-1.

vi Golden NH, Abrams SA. Optimizing bone health in children and adolescents. Pediatrics. 2014;134(4):e1229-1243. doi:10.1542/peds.2014-2173.
} 
significant differences between infants given $800 \mathrm{IU} / \mathrm{d}$ and smaller dosages.

Gallo et $\mathrm{al}^{1,2}$ and Rosendahl et al ${ }^{5}$ did not report significant differences in bone mass between infants given different dosages of vitamin D:

- Gallo et al ${ }^{1,2}$ compared infants given 400, 800, 1200, and $1600 \mathrm{IU} / \mathrm{d}$ of vitamin D3 from 1 to 12 months of age. No significant differences were observed in: (a) femur, lumbar spine, and whole-body BMC at $3,6,9$, and 12 months, (b) change in femur, lumbar spine, and whole-body BMC from 1 to 3, 3 to 6, 6 to 9 , and 9 to 12 months, (c) lumbar spine and whole-body BMC 36 months, (d) change in lumbar spine and whole-body BMC from 12 to 36 and 1 to 36 months, and (e) lumbar spine and whole-body BMD and BMD z-score at 36 months. It is possible that the lack of statistical significance is related to power. Study authors calculated that 25 participants per group would be sufficient to detect a $5 \%$ difference in whole-body BMD, and at the 36-month outcome measure, the analytic groups had between 6 and 25 participants, depending on the assessment.

- Rosendahl et al ${ }^{5}$ compared infants given 400 and $1200 \mathrm{lU} / \mathrm{d}$ of vitamin D3 from 2 weeks to 24 months and reported no significant differences in total bone and cortical bone BMC, BMD, cross-sectional area, and polar moment of inertia at 24 months. It is unlikely that the lack of statistical significance was related to power. Study authors calculated that 210 participants per group would permit detection of 0.2 SD difference in BMC and 297 participants per group would permit detection of 0.2 SD difference in the cross-sectional area; analytic groups were larger than these estimations ( $\mathrm{N}=343$ and 361).

Given the small number of studies and the inconsistency in results, there is insufficient evidence to determine the relationship between $400 \mathrm{IU} / \mathrm{d}$ of vitamin $\mathrm{D}$ from supplements, compared with higher dosages of vitamin $\mathrm{D}$ from supplements, and bone mass.

\section{Biomarkers of bone metabolism}

The evidence had strong consistency. None of the studies found significant differences in biomarkers of bone metabolism between different dosages and durations of vitamin $D$ supplementation.

Bone resorption biomarkers:

- Holmlund-Suila et $\mathrm{a}^{3}$ compared dosages of 400,1200 , and $1600 \mathrm{IU} / \mathrm{d}$ from 2 weeks to 3 months and found no significant differences in CTX at 3 months

- Ziegler et al ${ }^{6}$ compared 400,600, and $800 \mathrm{IU} / \mathrm{d}$ from 2 to 9 months and found no significant differences in CTX at 4, 5.5, 7.5, and 9 months

- Gallo et al ${ }^{2}$ compared dosages of $400,800,1200$, and $1600 \mathrm{IU} / \mathrm{d}$ from 1 to 12 months and found no significant differences in CTX at 36 months

Bone formation biomarkers:

- Holmlund-Suila et al ${ }^{3}$ compared dosages of 400,1200 , and $1600 \mathrm{IU} / \mathrm{d}$ from 2 weeks to 3 months and found no significant differences in PINP 3 months

- Ziegler et al ${ }^{6}$ compared 400,600, and $800 \mathrm{IU} / \mathrm{d}$ from 2 to 9 months and found no significant differences in ALP or osteocalcin at 4, 5.5, 7.5, and 9 months

Although the evidence had strong consistency, the analyses were heterogeneous. The studies assessed different biomarkers of bone formation (i.e., PINP, ALP, and osteocalcin). The studies assessed the same biomarker of bone resorption (i.e., CTX); however, it was assessed at different ages $(3,4,5.5,7.5,9$, and 36 months), in relation to different periods of supplementation 
$(2.5,7$, and 11 months), and during different phases of the study (within the supplementation period, at the end of the supplementation period, and 2 years after the supplementation period).

The evidence had limited precision; it is possible that the lack of statistical significance relates to insufficient statistical power. Two of the studies did not report power analyses, ${ }^{3,6}$ and the third study reported a power analysis related to BMD, but not CTX. ${ }^{2}$

The evidence has limited generalizability, as the participants in 2 of the 3 studies were predominantly ${ }^{2}$ or entirely ${ }^{6}$ White (the third study did not report race or ethnicity).

There was a moderate likelihood that the design and conduct of the studies prevented or minimized bias. The evidence was from randomized controlled trials, which had some risks of bias that varied between studies (Table 3).

Given this synthesis of the evidence, limited evidence suggests there is no relationship between consumption of $400 \mathrm{IU} / \mathrm{d}$ of vitamin $\mathrm{D}$ from supplements in infants younger than 12 months of age, compared with higher dosages of up to $1600 \mathrm{IU} / \mathrm{d}$, and biomarkers of bone metabolism followed up to 36 months of age.

\section{Comparisons of $\mathbf{4 0 0} \mathrm{IU} / \mathrm{d}$ with lower dosages of vitamin D}

One of the 5 studies compared $400 \mathrm{IU} / \mathrm{d}$ with a lower dosage. Ziegler et al ${ }^{6}$ compared infants given 400 or $200 \mathrm{IU} / \mathrm{d}$ of vitamin D3 from 2 to 9 months of age. There were no significant differences in whole-body BMC or BMD at the end of winter (i.e., 5.5-9 months). There were also no significant differences in alkaline phosphatase, osteocalcin, and CTX at 4, 5.5, 7.5, and 9 months.

This is insufficient evidence to determine the relationship between $400 \mathrm{IU} / \mathrm{d}$ of vitamin $\mathrm{D}$ from supplements, compared with lower dosages, and bone health.

\section{Comparisons of $200 \mathrm{IU} / \mathrm{d}$ for different durations with a placebo}

One of the 5 studies compared $200 \mathrm{IU}$ for different durations (i.e., birth to 6 months and 2 to 6 months) with a placebo. Ponnapakkam et $\mathrm{al}^{4}$ found no significant differences in ALP at 2, 4, and 6 months, and no cases of rickets in any of the participants.

This is insufficient evidence to determine the relationship between vitamin $D$ from supplements, compared with no vitamin D from supplements, and bone health. 
Table 2. Evidence examining the relationship between vitamin D from supplements consumed during infancy and toddlerhood and bone health

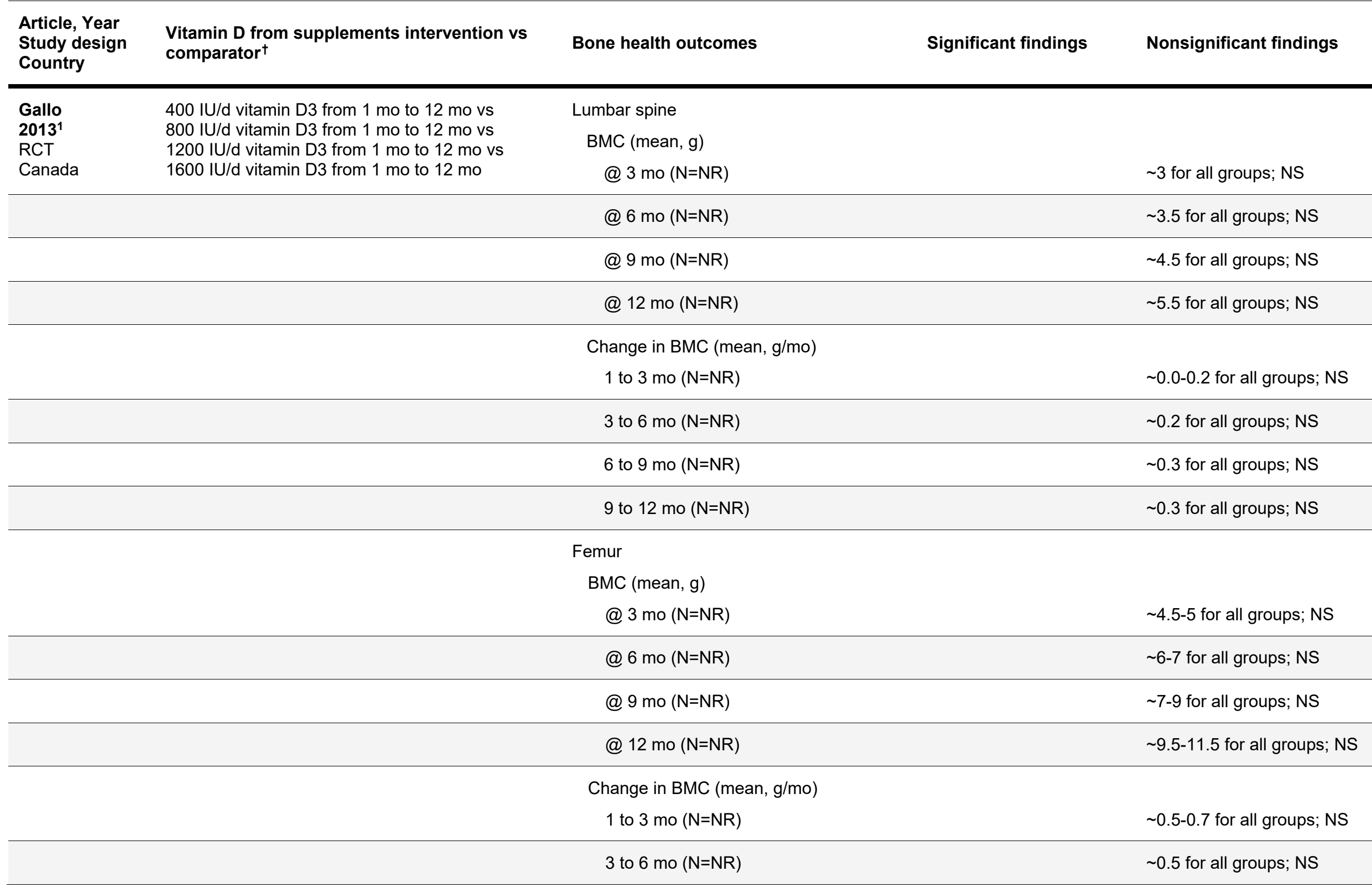




\begin{tabular}{|c|c|c|c|}
\hline $\begin{array}{l}\text { Article, Year } \\
\text { Study design } \\
\text { Country }\end{array}$ & $\begin{array}{l}\text { Vitamin D from supplements intervention vs } \\
\text { comparator }^{\dagger}\end{array}$ & Bone health outcomes & Nonsignificant findings \\
\hline & & 6 to $9 \mathrm{mo}(\mathrm{N}=\mathrm{NR})$ & $\sim 0.5-0.7$ for all groups; NS \\
\hline & & 9 to $12 \mathrm{mo}(\mathrm{N}=\mathrm{NR})$ & $\sim 0.5-1.3$ for all groups; NS \\
\hline \multicolumn{4}{|c|}{ Whole-body } \\
\hline \multicolumn{4}{|c|}{ BMC (mean, g) } \\
\hline & & @ 3 mo (N=NR) & $\sim 130-140$ for all groups; NS \\
\hline & & @ 6 mo (N=NR) & $\sim 160-180$ for all groups; NS \\
\hline & & @ 9 mo (N=NR) & 〜200 for all groups; NS \\
\hline & & @ 12 mo (N=NR) & $\sim 230-250$ for all groups; NS \\
\hline \multicolumn{4}{|c|}{ Change in BMC (mean, $\mathrm{g} / \mathrm{mo}$ ) } \\
\hline & & 1 to $3 \mathrm{mo}(\mathrm{N}=\mathrm{NR})$ & $\sim 15-18$ for all groups; NS \\
\hline & & 3 to $6 \mathrm{mo}(\mathrm{N}=\mathrm{NR})$ & $\sim 12-15$ for all groups; NS \\
\hline & & 6 to $9 \mathrm{mo}(\mathrm{N}=\mathrm{NR})$ & $\sim 7-12$ for all groups; NS \\
\hline & & 9 to $12 \mathrm{mo}(\mathrm{N}=\mathrm{NR})$ & 7-12 for all groups; NS \\
\hline \multirow{3}{*}{$\begin{array}{l}\text { Gallo } \\
2016^{2} \\
\text { RCT } \\
\text { Canada }\end{array}$} & \multirow{3}{*}{$\begin{array}{l}400 \mathrm{IU} / \mathrm{d} \text { vitamin D3 from } 1 \mathrm{mo} \text { to } 12 \mathrm{mo} \text { vs } \\
800 \mathrm{IU} / \mathrm{d} \text { vitamin D3 from } 1 \mathrm{mo} \text { to } 12 \mathrm{mo} \text { vs } \\
1200 \mathrm{IU} / \mathrm{d} \text { vitamin D3 from } 1 \mathrm{mo} \text { to } 12 \mathrm{mo} \text { vs } \\
1600 \mathrm{IU} / \mathrm{d} \text { vitamin D3 from } 1 \mathrm{mo} \text { to } 12 \mathrm{mo}\end{array}$} & Lumbar spine, vertebrae L1-L4 & \\
\hline & & $\begin{array}{l}\mathrm{BMC}(\operatorname{mean}[95 \% \mathrm{Cl}], \mathrm{g}) @ 36 \mathrm{mo} \\
(\mathrm{N}=25,24,25,11)\end{array}$ & $\begin{array}{l}11.5[10.8,12.2] \mathrm{vs} \\
11.4[10.8,12.0] \mathrm{vs} \\
11.8[11.3,12.3] \mathrm{vs} \\
11.6[10.3,12.9] ; \\
\mathrm{p}=0.865\end{array}$ \\
\hline & & $\begin{array}{l}\mathrm{BMD}(\operatorname{mean}[95 \% \mathrm{Cl}], \mathrm{g} / \mathrm{cm} 2) @ 36 \mathrm{mo} \\
(\mathrm{N}=25,24,25,11)\end{array}$ & $\begin{array}{l}0.474[0.450,0.500] \text { vs } \\
0.463[0.445,0.481] \text { vs } \\
0.479[0.462,0.496] \text { vs } \\
0.463[0.429,0.498] ; \\
p=0.655\end{array}$ \\
\hline
\end{tabular}




\section{Article, Year \\ Study design \\ Vitamin D from supplements intervention vs comparator $^{\dagger}$}

Country
Bone health outcomes

Significant findings

Nonsignificant findings

BMD Z-score (mean [95\% Cl]) @ 36 mo

$(\mathrm{N}=25,24,25,11)$

$0.46[0.05,0.97]$ vs

$0.18[-0.22,0.59]$ vs

$0.62[0.25,0.98]$ vs

$-0.18[-0.56,0.92]$;

$p=0.457$

Change in BMC (mean [95\% Cl], g)

from 12 to $36 \mathrm{mo}(\mathrm{N}=24,24,24,11)$

$5.71[4.96,6.47]$ vs $5.74[4.55,6.93]$ vs

$6.13[5.61,6.65]$ vs

5.89 [4.84, 6.95];

$\mathrm{p}=0.882$

from 1 to $36 \mathrm{mo}(\mathrm{N}=25,24,25,11)$

$8.48[7.82,9.14]$ vs

$8.83[8.29,9.37]$ vs

$9.00[8.36,9.65]$ vs

$8.62[7.47,9.76]$

$\mathrm{p}=0.652$

\section{Whole body}

BMC (mean [95\% Cl], g) @ 36 mo

$(\mathrm{N}=24,23,25,10)$

$600.6[578.9,622.3]$ vs $593.1[575.4,610.7]$ vs

$593.1[576.5,609.6]$ vs $633.1[591.5,674.9]$; $p=0.110$

BMD (mean [95\% Cl], g/cm²) @ 36 mo

$(\mathrm{N}=24,23,25,10)$

$0.622[0.607,0.637]$ vs $0.626[0.611,0.642] \mathrm{vs}$

$0.618[0.604,0.633]$ vs $0.651[0.615,0.686]$; $p=0.133$

BMD Z-score (mean [95\% Cl]) @ 36 mo $(\mathrm{N}=24,23,25,10)$

$2.00[1.53,2.47]$ vs $1.97[1.58,2.36]$ vs

$1.83[1.46,2.19]$ vs

$2.61[1.63,3.59]$

$p=0.245$ 


\section{Article, Year \\ Study design \\ Vitamin D from supplements intervention vs comparator $^{\dagger}$}

Country
Bone health outcomes

Significant findings

Nonsignificant findings

Change in BMC (mean [95\% Cl], g)

from 12 to $36 \mathrm{mo}(\mathrm{N}=18,21,21,6)$

$354.2[329.8,378.6]$ vs $362.10[345.3,378.9]$ vs $361.7[346.0,377.5]$ vs 388.7 [333.4, 444.1];

$\mathrm{p}=0.377$

from 1 to $36 \mathrm{mo}(\mathrm{N}=24,23,25,10)$

$497.0[474.6,519.5]$ vs $496.6[479.0,514.2]$ vs $493.5[475.3,511.8]$ vs 534.0 [492.0, 576.0]; $p=0.931$

Plasma C-terminal telopeptide of type I collagen (CTX) (mean [95\% Cl], ng/mL) @

$36 \mathrm{mo}(\mathrm{N}=\mathrm{NR})$

\begin{abstract}
Holmlund-
Suila $2012^{3}$

RCT

$400 \mathrm{IU} / \mathrm{d}$ vitamin D3 from 2 wk to $3 \mathrm{mo}$ vs

$1200 \mathrm{lU} / \mathrm{d}$ vitamin D3 from 2 wk to $3 \mathrm{mo}$ vs

$1600 \mathrm{lU} / \mathrm{d}$ vitamin D3 from 2 wk to $3 \mathrm{mo}$
\end{abstract}

Finland

\section{Total and trabecular bone}

BMD (mean \pm SE, mg/cm ${ }^{3}$ ) @ 3 mo

$(\mathrm{N}=25,29,28)$
$448 \pm 13$ vs

$430 \pm 12$ vs

$451 \pm 12$

$p=0.387$
Cross sectional area (mean $\pm \mathrm{SE}, \mathrm{mm}^{2}$ )

@ 3 mo $(\mathrm{N}=25,29,28)$

\section{$72 \pm 3$ vs \\ $77 \pm 3$ vs \\ $81 \pm 3^{*}$ \\ $\mathrm{p}=0.069$}

Cross sectional area

(mm2) significantly higher

in 1600 IU/d group than

in $400 \mathrm{lU} / \mathrm{d}$ group

$(p=0.022)$

\section{Cortical bone}

BMD (mean $\left.\pm \mathrm{SE}, \mathrm{mg} / \mathrm{cm}^{3}\right) @ 3 \mathrm{mo}$

$(\mathrm{N}=25,29,28)$ 


\section{Article, Year \\ Study design \\ Vitamin D from supplements intervention vs comparator $^{\dagger}$}

Country
Bone health outcomes

Significant findings

Nonsignificant findings

Cross sectional area (mean $\left.\pm \mathrm{SE}, \mathrm{mm}^{2}\right)$

@ 3 mo ( $\mathrm{N}=25,29,28)$

\section{$31 \pm 1$ vs \\ $32 \pm 1$ vs \\ $34 \pm 1^{*}$; \\ $\mathrm{p}=0.053$}

Cross sectional area

(mm2) significantly higher

in $1600 \mathrm{lU} / \mathrm{d}$ group than

$400 \mathrm{IU} / \mathrm{d}$ group $(p=0.027)$

and $1200 \mathrm{IU} / \mathrm{d}$ group

$(p=0.050)$

Polar stress and strain index (mean $\pm \mathrm{SE}$

$\left.\mathrm{mm}^{3}\right) @ 3 \mathrm{mo}(\mathrm{N}=25,29,28)$
$48 \pm 2$ vs

$54 \pm 2^{*}$

$\mathrm{p}=0.070$

Polar stress and strain

index (mm3) significantly

higher in $1600 \mathrm{IU} / \mathrm{d}$ group

than $400 \mathrm{IU} / \mathrm{d}$ group

$(p=0.043)$ and $1200 \mathrm{lU} / \mathrm{d}$

group $(p=0.050)$

\begin{tabular}{|c|c|c|c|}
\hline & & $\begin{array}{l}\text { Procollagen I N-terminal propeptide (PINP) } \\
\text { (mean, } \mu \mathrm{g} / \mathrm{L}) @ 3 \text { mo }(\mathrm{N}=25,29,28)\end{array}$ & 2.2 vs 2.1 vs $2.0 ; p=0.992$ \\
\hline & & $\begin{array}{l}\text { C-terminal cross-linked telopeptides of type } \\
\text { I collagen (mean, } \mu \mathrm{g} / \mathrm{L}) @ 3 \mathrm{mo}(\mathrm{N}=25,29 \text {, } \\
\text { 28) }\end{array}$ & 1.4 vs 1.4 vs $1.3 ; p=0.757$ \\
\hline \multirow{4}{*}{ 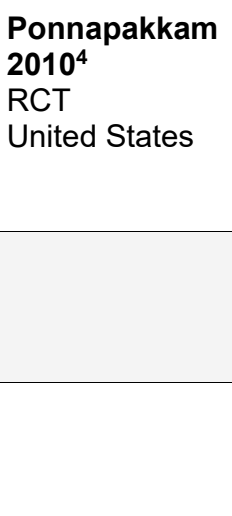 } & \multirow{2}{*}{$\begin{array}{l}200 \mathrm{IU} / \mathrm{d} \text { vitamin D3 from birth to } 6 \mathrm{mo} \text { vs } \\
200 \mathrm{IU} / \mathrm{d} \text { vitamin D3 from } 2 \text { mo to } 6 \mathrm{mo} \text { vs } \\
\text { placebo from birth to } 6 \mathrm{mo}\end{array}$} & $\begin{array}{l}\text { Serum alkaline phosphatase (mean } \pm \mathrm{SE} \text {, } \\
\mathrm{IU} / \mathrm{L} \text { ) }\end{array}$ & \\
\hline & & @ 2 mo $(\mathrm{N}=33)$ & $\begin{array}{l}\sim 135 \pm 15 \text { vs } \\
\sim 137 \pm 15 \text { vs } \\
\sim 125 \pm 10 ; \text { NS }\end{array}$ \\
\hline & & @ 4 mo $(\mathrm{N}=22)$ & $\begin{array}{l}\sim 137 \pm 25 \text { vs } \\
\sim 100 \pm 10 \text { vs } \\
\sim 120 \pm 15 ; \mathrm{NS}\end{array}$ \\
\hline & & @ 6 mo $(\mathrm{N}=25)$ & $\begin{array}{l}\sim 140 \pm 20 \text { vs } \\
\sim 100 \pm 15 \text { vs } \\
\sim 80 \pm 10 ; \text { NS }\end{array}$ \\
\hline
\end{tabular}




\section{Article, Year \\ Study design \\ Country \\ Vitamin D from supplements intervention vs comparator $^{\dagger}$}

\begin{tabular}{|c|c|c|c|}
\hline & & Incidence of rickets & \\
\hline & & @ 2 mo (N=NR) & No infants with rickets; NS \\
\hline & & @ 4 mo (N=NR) & No infants with rickets; NS \\
\hline & & @ 6 mo (N=NR) & No infants with rickets; NS \\
\hline \multirow{10}{*}{$\begin{array}{l}\text { Rosendahl, } \\
2018^{5} \\
\text { RCT } \\
\text { Finland }\end{array}$} & $400 \mathrm{IU} / \mathrm{d}$ vitamin D3 from 2 wk to 24 mo vs & Total bone & \\
\hline & 1200 IU/d vitamin D3 from 2 wk to 24 mo & $\begin{array}{l}\text { BMC (mean difference }[95 \% \mathrm{Cl}] \\
\mathrm{mg} / \mathrm{mm}) @ 24 \mathrm{mo}(\mathrm{N}=343,361)\end{array}$ & $0.4[-0.8,1.6] ; \mathrm{NS}$ \\
\hline & & $\begin{array}{l}\text { BMD (mean difference }[95 \% \mathrm{Cl}] \\
\mathrm{mg} / \mathrm{cm} 3) @ 24 \mathrm{mo}(\mathrm{N}=343,361)\end{array}$ & $2.9[-8.3,14.2] ; \mathrm{NS}$ \\
\hline & & $\begin{array}{l}\text { Cross sectional area (mean difference } \\
[95 \% \mathrm{Cl}], \mathrm{mm} 2) @ 24 \mathrm{mo}(\mathrm{N}=343,361)\end{array}$ & $-0.9[-5.0,3.2] ; \mathrm{NS}$ \\
\hline & & $\begin{array}{l}\text { Polar moment of inertia (mean difference } \\
[95 \% \mathrm{Cl}], \mathrm{mm} 4) @ 24 \mathrm{mo}(\mathrm{N}=343,361)\end{array}$ & $-66.0[-274.3,142.3] ; \mathrm{NS}$ \\
\hline & & Cortical bone & \\
\hline & & $\begin{array}{l}\text { BMC (mean difference }[95 \% \mathrm{Cl}] \\
\mathrm{mg} / \mathrm{mm}) @ 24 \mathrm{mo}(\mathrm{N}=343,361)\end{array}$ & $1.0[-0.4,2.4] ; \mathrm{NS}$ \\
\hline & & $\begin{array}{l}\text { BMD (mean difference }[95 \% \mathrm{Cl}] \\
\left.\mathrm{mg} / \mathrm{cm}^{3}\right) @ 24 \mathrm{mo}(\mathrm{N}=343,361)\end{array}$ & $6.0[-3.2,15.2] ; \mathrm{NS}$ \\
\hline & & $\begin{array}{l}\text { Cross sectional area (mean difference } \\
\left.[95 \% \mathrm{Cl}], \mathrm{mm}^{2}\right) @ 24 \mathrm{mo}(\mathrm{N}=343,361)\end{array}$ & $1.0[-0.4,2.4] ; \mathrm{NS}$ \\
\hline & & $\begin{array}{l}\text { Polar moment of inertia (mean difference } \\
\left.[95 \% \mathrm{Cl}], \mathrm{mm}^{4}\right) @ 24 \mathrm{mo}(\mathrm{N}=343,361)\end{array}$ & $9.9[-69.1,88.9] ; \mathrm{NS}$ \\
\hline \multirow{2}{*}{$\begin{array}{l}\text { Ziegler } \\
2017^{6} \\
\text { RCT } \\
\text { United States }\end{array}$} & \multirow{2}{*}{$\begin{array}{l}200 \mathrm{lU} / \mathrm{d} \text { vitamin D3 from } 2 \mathrm{mo} \text { to } 9 \mathrm{mo} \text { vs } \\
400 \mathrm{lU} / \mathrm{d} \text { vitamin D3 from } 2 \mathrm{mo} \text { to } 9 \mathrm{mo} \text { vs } \\
600 \mathrm{lU} / \mathrm{d} \text { vitamin D3 from } 2 \text { mo to } 9 \mathrm{mo} \text { vs } \\
800 \mathrm{lU} / \mathrm{d} \text { vitamin D3 from } 2 \text { mo to } 9 \mathrm{mo}\end{array}$} & $\begin{array}{l}\text { Bone-specific alkaline phosphatase (mean } \\
\pm \mathrm{SD}, \mathrm{IU} / \mathrm{L})\end{array}$ & \\
\hline & & @ $4 \mathrm{mo}(\mathrm{N}=46,44,42,33)$ & $\begin{array}{l}167 \pm 42 \text { vs } \\
188 \pm 51 \text { vs } \\
168 \pm 41 \text { vs } \\
194 \pm 56^{\ddagger} ; \mathrm{NS}\end{array}$ \\
\hline
\end{tabular}

\section{Bone health outcomes}

Significant findings
Nonsignificant findings

ncidence of rickets

No infants with rickets; NS 


\section{Article, Year \\ Study design \\ Vitamin D from supplements intervention vs comparator $^{\dagger}$}

Country
Bone health outcomes

Significant findings

Nonsignificant findings

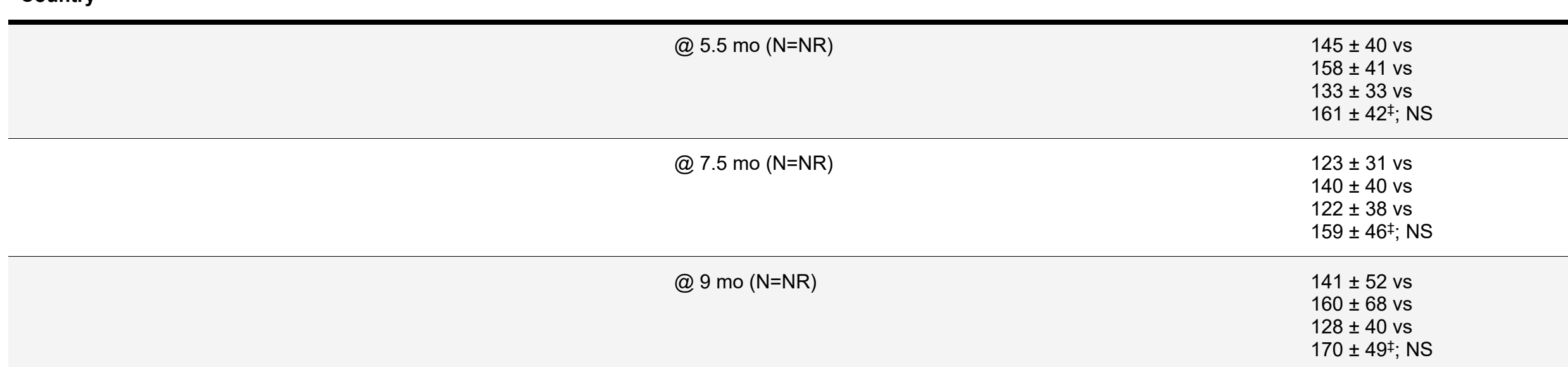

Osteocalcin (mean $\pm \mathrm{SD}, \mathrm{mcg} / \mathrm{L})$

@ $4 \mathrm{mo}(\mathrm{N}=46,44,42,33)$

$16.8 \pm 4$ vs

$17.4 \pm 6.5$ vs

$18.7 \pm 6.0$ vs

$16.8 \pm 5.4 ; \mathrm{NS}$

@ $5.5 \mathrm{mo}(\mathrm{N}=\mathrm{NR})$

$16.7 \pm 4$ vs

$15.3 \pm 6.3$ vs

$17.2 \pm 5.6$ vs

$14.4 \pm 4.3 ; \mathrm{NS}$

@ $7.5 \mathrm{mo}(\mathrm{N}=\mathrm{NR})$

$19.7 \pm 5$ vs

$18.5 \pm 6.6$ vs

$20.5 \pm 7.7$ vs

$17.0 \pm 7.0 ; \mathrm{NS}$

@ $9 \mathrm{mo}(\mathrm{N}=\mathrm{NR})$

$23.0 \pm 6$ vs

$22.4 \pm 6.8$ vs

$24.8 \pm 6.7$ vs

$19.3 \pm 8.4 ; \mathrm{NS}$

C-terminal telopeptides (mean $\pm \mathrm{SD}$,

$\mathrm{mcg} / \mathrm{L}$ )

@ 4 mo $(\mathrm{N}=45,43,42,30)$

$1.21 \pm 0.30$ vs

$1.23 \pm 0.26$ vs

$1.21 \pm 0.36$ vs

$1.32 \pm 0.31 ; \mathrm{NS}$ 


\section{Article, Year \\ Study design \\ Vitamin D from supplements intervention vs comparator $^{\dagger}$}

Country
Bone health outcomes

Significant findings

Nonsignificant findings

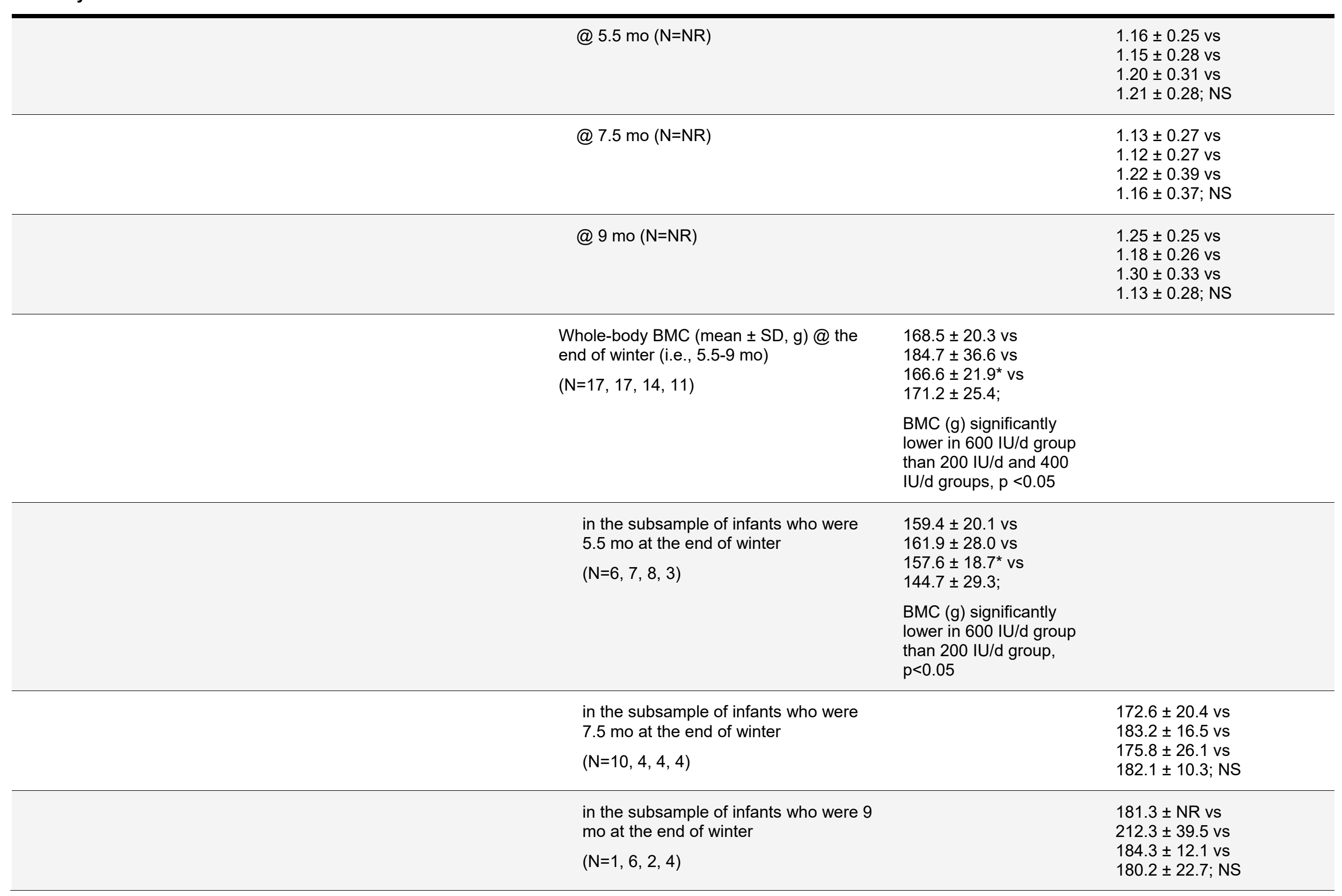




\section{Article, Year \\ Study design \\ Vitamin D from supplements intervention vs comparator $^{\dagger}$}

Country
Bone health outcomes

Significant findings

Nonsignificant findings
Whole-body BMC (mean \pm SD, g/kg) @ the end of winter (i.e., 5.5-9 mo)

$(\mathrm{N}=17,17,14,11)$
$22.37 \pm 1.47$ vs

$22.56 \pm 1.61 \mathrm{vs}$

$21.02 \pm 1.54^{*}$ vs

$22.00 \pm 1.48$

BMC $(\mathrm{g} / \mathrm{kg})$ significantly

lower in $600 \mathrm{lU} / \mathrm{d}$ group

than $200 \mathrm{lU} / \mathrm{d}$ and 400

IU/d groups, $p<0.05$

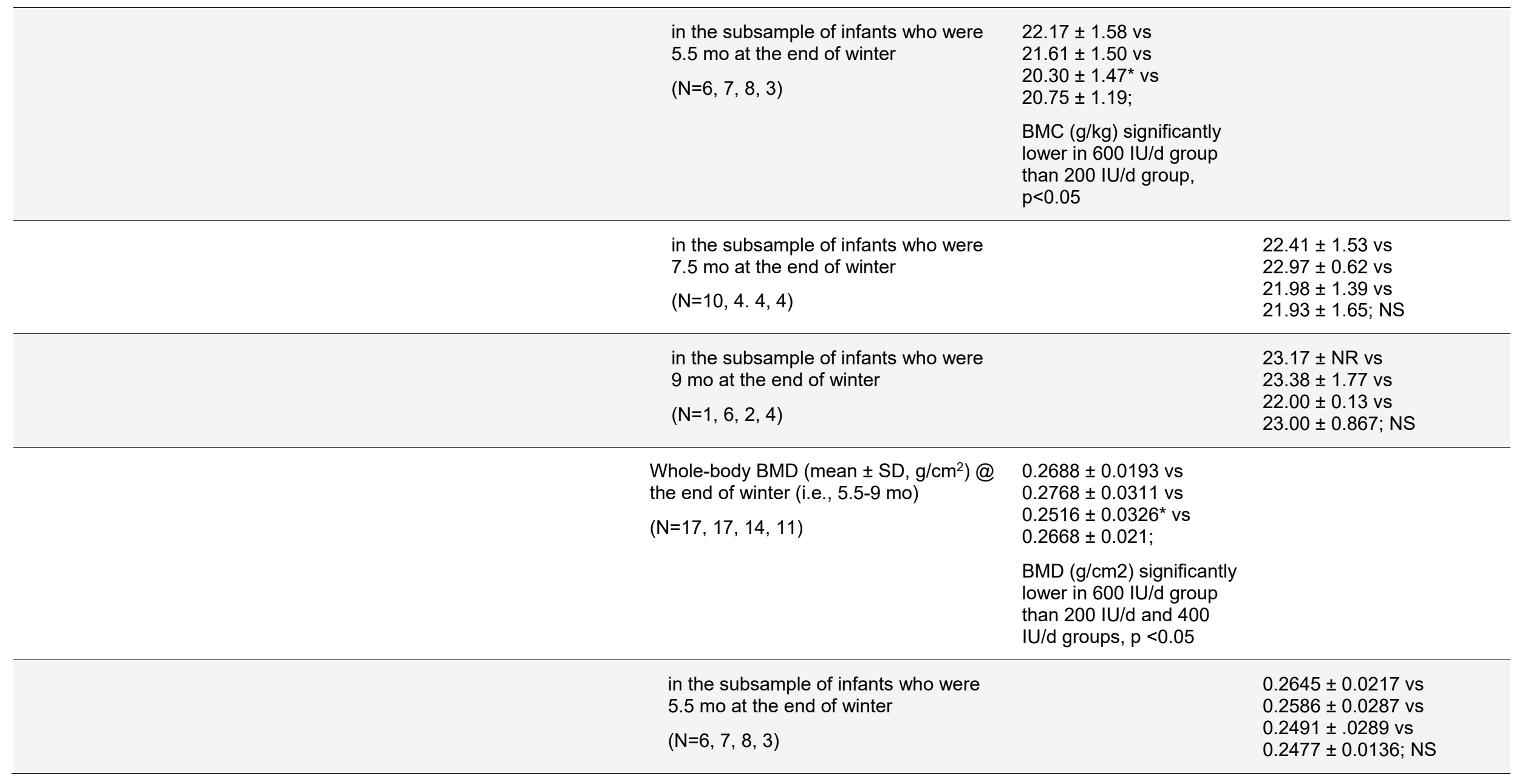




\section{Article, Year \\ Study design \\ Vitamin D from supplements intervention vs comparator $^{\dagger}$}

Country
Bone health outcomes

Significant findings
Nonsignificant findings

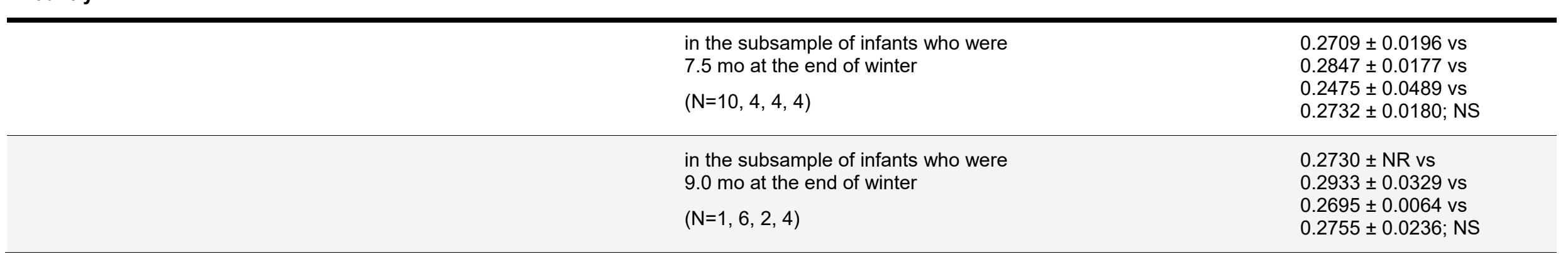

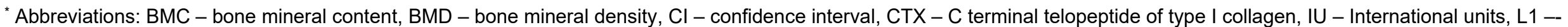

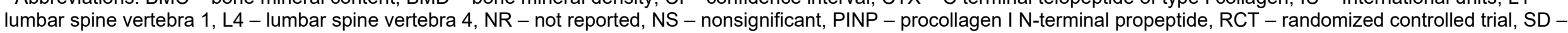
standard deviation, SE - standard error

$\dagger$ Interventions and comparators, from the articles included in the body of evidence, which compare vitamin $D$ from supplements with different dosages of vitamin $D$ from supplements or a placebo.

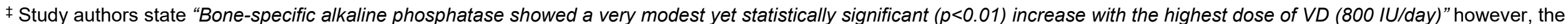
results reported in the table are not marked as statistically significant. 
Table 3. Risk of bias for randomized controlled trials examining consumption of vitamin D from supplements during infancy and toddlerhood and bone health ${ }^{*}$

\begin{tabular}{|c|c|c|c|c|c|c|}
\hline & Randomization & $\begin{array}{l}\text { Identification of } \\
\text { participants - } \\
\text { randomization }\end{array}$ & $\begin{array}{c}\text { Deviations from } \\
\text { intended } \\
\text { interventions }\end{array}$ & $\begin{array}{c}\text { Missing outcome } \\
\text { data }\end{array}$ & $\begin{array}{c}\text { Outcome } \\
\text { measurement }\end{array}$ & $\begin{array}{l}\text { Selection of the } \\
\text { reported result }\end{array}$ \\
\hline Gallo, 2013 ${ }^{1}$ & Low & Low & Low & Some Concerns & Low & Low \\
\hline Gallo, $2016^{2}$ & Low & Low & Some Concerns & Some Concerns & Low & Some Concerns \\
\hline Holmlund-Suila, $2012^{3}$ & Low & Low & Low & Low & Some Concerns & Low \\
\hline Ponnapakkam, $2010^{4}$ & High & High & High & High & High & High \\
\hline Rosendahl, $2018^{5}$ & Low & Low & Low & Low & Low & Low \\
\hline Ziegler, $2017^{6}$ & Some Concerns & Low & High & High & Low & High \\
\hline
\end{tabular}

* A detailed description of the methodology used for assessing risk of bias is available on the NESR website: https://nesr.usda.gov/2020-dietary-guidelinesadvisory-committee-systematic-reviews and in Part C of the following reference: Dietary Guidelines Advisory Committee. 2020. Scientific Report of the 2020 Dietary Guidelines Advisory Committee: Advisory Report to the Secretary of Agriculture and the Secretary of Health and Human Services. U.S. Department of Agriculture, Agricultural Research Service, Washington, DC.

† Possible ratings of low, some concerns, or high determined using the "Cochrane Risk-of-bias 2.0" (RoB 2.0) (August 2016 version)" (Higgins JPT, Sterne JAC, Savović J, Page MJ, Hróbjartsson A, Boutron I, Reeves B, Eldridge S. A revised tool for assessing risk of bias in randomized trials In: Chandler J, McKenzie J, Boutron I, Welch V (editors). Cochrane Methods. Cochrane Database of Systematic Reviews 2016, Issue 10 (Suppl 1). dx.doi.org/10.1002/14651858.CD201601.) 


\section{Research recommendations}

Investigate how much (if any) vitamin D supplementation is needed for bone health under the following circumstances:

a) When the mother is taking high doses of vitamin $D$, and

b) When the infant has short periods of sun exposure in certain latitudes.

Future studies should be appropriately powered, include racially and ethnically diverse samples, and report baseline vitamin D status, human milk vitamin D content, and sun exposure.

\section{Included articles}

1. Gallo S, Comeau K, Vanstone C, et al. Effect of different dosages of oral vitamin D supplementation on vitamin $\mathrm{D}$ status in healthy, breastfed infants: a randomized trial. JAMA. 2013;309(17):1785-1792.doi: 10.1001/jama.2013.3404.

2. Gallo $S$, Hazell $T$, Vanstone $C A$, et al. Vitamin $D$ supplementation in breastfed infants from Montreal, Canada: 25-hydroxyvitamin $D$ and bone health effects from a follow-up study at 3 years of age. Osteoporos Int. 2016;27(8):2459-2466.doi: 10.1007/s00198-016-3549-z.

3. Holmlund-Suila E, Viljakainen H, Hytinantti T, Lamberg-Allardt C, Andersson S, Makitie O. High-dose vitamin d intervention in infants--effects on vitamin d status, calcium homeostasis, and bone strength. J Clin Endocrinol Metab. 2012;97(11):4139-4147.doi: 10.1210/jc.2012-1575.

4. Ponnapakkam T, Bradford E, Gensure R. A treatment trial of vitamin D supplementation in breast-fed infants: universal supplementation is not necessary for rickets prevention in Southern Louisiana. Clin Pediatr (Phila). 2010;49(11):1053-1060.doi: 10.1177/0009922810376320.

5. Rosendahl J, Valkama S, Holmlund-Suila E, et al. Effect of Higher vs Standard Dosage of Vitamin D3 Supplementation on Bone Strength and Infection in Healthy Infants: A Randomized Clinical Trial. JAMA Pediatr. 2018;172(7):646-654.doi: 10.1001/jamapediatrics.2018.0602.

6. Ziegler EE, Koo WW, Nelson SE, Jeter JM. Lack of Effect of Graded Doses of Vitamin D on Bone Metabolism of Breastfed Infants. J Clin Nutr Metab. 2017;1(1).doi. 


\section{METHODOLOGY}

The NESR team used its rigorous, protocol-driven methodology to support the 2020 Dietary Guidelines Advisory Committee in conducting this systematic review.

NESR's systematic review methodology involves:

- Developing a protocol,

- Searching for and selecting studies,

- Extracting data from and assessing the risk of bias of each included study,

- Synthesizing the evidence,

- Developing conclusion statements,

- Grading the evidence underlying the conclusion statements, and

- Recommending future research.

A detailed description of the methodology used in conducting this systematic review is available on the NESR website: https://nesr.usda.gov/2020-dietary-guidelines-advisory-committee-systematicreviews, and can be found in the 2020 Dietary Guidelines Advisory Committee Report, Part C: Methodology. vii This systematic review was peer reviewed by Federal scientists, and information about the peer review process can also be found in the Committee's Report, Part C. Methodology. Additional information about this systematic review, including a description of and rationale for any modifications made to the protocol can be found in the 2020 Dietary Guidelines Advisory Committee Report, Chapter 6. Nutrients from Dietary Supplements During Infancy and Toddlerhood.

Below are details of the final protocol for the systematic review described herein, including the:

- Analytic framework

- Literature search and screening plan

- Literature search and screening results

vii Dietary Guidelines Advisory Committee. 2020. Scientific Report of the 2020 Dietary Guidelines Advisory Committee: Advisory Report to the Secretary of Agriculture and the Secretary of Health and Human Services. U.S. Department of Agriculture, Agricultural Research Service, Washington, DC. 
The analytic framework (Figure 1) illustrates the overall scope of the systematic review, including the population, the interventions and/or exposures, comparators, and outcomes of interest. It also includes definitions of key terms and identifies key confounders and other factors considered in the systematic review. The inclusion and exclusion criteria that follow provide additional information about how parts of the analytic framework were defined and operationalized for the review.

\section{Figure 1: Analytic framework}

\section{Systematic review question: What is the relationship between vitamin D from supplements consumed during} infancy and toddlerhood and bone health?

Intervention/ exposure

Consumption of vitamin D

from supplements vs

Comparator

Consumption of vitamin D:

a) at a different dosage or frequency from supplements

b) from fortified foods

Population: Infants and toddlers (birth to 24 months); full-term, healthy and/or at risk for chronic disease)

\section{Health outcomes}

- Bone mass, including

- bone mineral density

- bone mineral content

- Biomarkers of bone metabolism

- Rickets

- Fracture

Population: Infants and toddlers (birth to 24 months), children and adolescents (2 to 18 years)

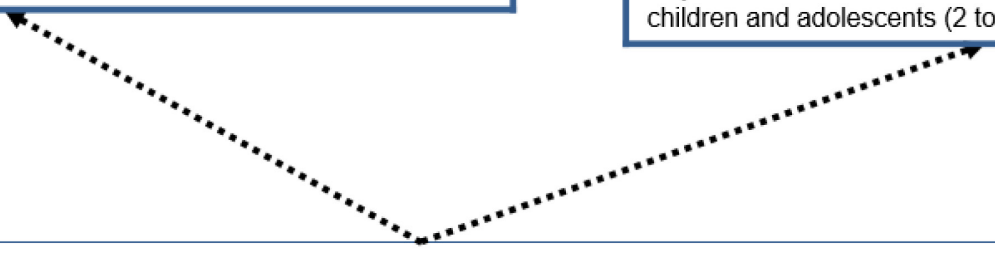

Key Confounders: Sex, Race/ethnicity, Socioeconomic status, Parental education, Feeding practices (e.g., human milk/infant formula history), Use of foods that are fortified or rich in the nutrient of interest (in supplements studies), Anthropometry at birth or baseline, Gestational age

Other factors to be considered: Vegetarian diet (child), Sun exposure and sunscreen usage, Maternal vitamin-supplement use, Baseline nutrient status Physical activity, Maternal age

\section{Key definitions}

- Dietary Supplement - a product (other than tobacco) that: is intended to supplement the diet; contains one or more dietary ingredients (including vitamins; minerals; herbs or other botanicals; amino acids; and other substances) or their constituents; is intended to be taken by mouth as a pill, capsule, tablet, or liquid; and is labeled on the front panel as being a dietary supplement. (ODS, Dietary Supplement Health and Education Act, 1994)

- Fortification - as defined by the U.S. Food and Drug Administration (FDA), the deliberate addition of one or more essential nutrients to a food, whether or not it is normally contained in the food. Fortification may be used to prevent or correct a demonstrated deficiency in the population or specific population groups; restore naturally occurring nutrients lost during processing, storage, or handling; or to add a nutrient to a food at the level found in a comparable traditional food. When cereal grains are labeled as enriched, it is mandatory that they be fortified with folic acid

\section{Legend}

$\longrightarrow$ The relationship of interest in the systematic review

Factors that may impact the relationship of interest in the systematic review 


\section{LITERATURE SEARCH AND SCREENING PLAN}

\section{Inclusion and exclusion criteria}

This table provides the inclusion and exclusion criteria for the systematic review. The inclusion and exclusion criteria are a set of characteristics used to determine which articles identified in the literature search were included in or excluded from the systematic review.

Table 4. Inclusion and exclusion criteria

\begin{tabular}{lll} 
Category & Inclusion Criteria & Exclusion Criteria \\
\hline Study design & - Randomized controlled trials & - Uncontrolled trials \\
& - Non-randomized controlled trials, & - Case-control studies \\
including quasi-experimental and & controlled before and after studies & - Cross-sectional studies \\
& - Prospective cohort studies & - Uncontrolled before-and-after \\
- Retrospective cohort studies & - Nadies \\
& - Nested case-control studies & - Systematic reviews \\
& & - Meta-analyses \\
\hline
\end{tabular}

$\begin{array}{ll}\begin{array}{l}\text { Intervention/ } \\ \text { exposure }\end{array} & \begin{array}{l}\text { Studies that examine consumption } \\ \text { of vitamin D from supplements }\end{array} \\ - & \begin{array}{l}\text { Studies that specify the } \\ \text { dosage/amount of vitamin D } \\ \text { received }\end{array}\end{array}$

- Studies that do not specify the dosage/amount level of vitamin D received

- Studies that vary nutrients other than vitamin $\mathrm{D}$ without controlling for that variation
Comparator
- Studies that compare consumption
of vitamin $D$
- at a different dosage or frequency from supplements
o from fortified foods

- N/A
Outcomes
- Bone mass, including:
- N/A
- bone mineral density
o bone mineral content
- Biomarkers of bone metabolism
- Rickets
- Fracture
Date of
- January 2000 - January 2020 publication 


\begin{tabular}{|c|c|c|}
\hline Category & Inclusion Criteria & Exclusion Criteria \\
\hline $\begin{array}{l}\text { Publication } \\
\text { status }\end{array}$ & $\begin{array}{l}\text { - Articles that have been peer- } \\
\text { reviewed }\end{array}$ & $\begin{array}{l}\text { - Articles that have not been peer- } \\
\text { reviewed and are not published in } \\
\text { peer-reviewed journals (e.g., } \\
\text { unpublished data, manuscripts, } \\
\text { pre-prints, reports, abstracts, and } \\
\text { conference proceedings) }\end{array}$ \\
\hline $\begin{array}{l}\text { Language of } \\
\text { publication }\end{array}$ & - Articles published in English & $\begin{array}{l}\text { - Articles published in languages } \\
\text { other than English }\end{array}$ \\
\hline Country viii & $\begin{array}{l}\text { - Studies conducted in countries } \\
\text { ranked as high or higher human } \\
\text { development }\end{array}$ & $\begin{array}{l}\text { - Studies conducted in countries } \\
\text { ranked as medium or lower human } \\
\text { development }\end{array}$ \\
\hline $\begin{array}{l}\text { Study } \\
\text { participants }\end{array}$ & $\begin{array}{l}\text { - Human participants } \\
\text { - Males } \\
\text { - Females }\end{array}$ & Non-human participants (i.e., animals) \\
\hline $\begin{array}{l}\text { Age of study } \\
\text { participants }\end{array}$ & $\begin{array}{l}\text { - Age at intervention or exposure: } \\
\circ \quad \text { Infants and toddlers (0-24 } \\
\text { months) } \\
\text { - Age at outcome: } \\
\circ \quad \text { Infants and toddlers (0-24 } \\
\text { months) } \\
\circ \text { Children and adolescents (2- } \\
18 \text { years) }\end{array}$ & $\begin{array}{l}\text { - Age at intervention or exposure: } \\
\circ \text { Children and adolescents } \\
(2-18 \text { years) } \\
\circ \text { Adults (19 years and older) } \\
\text { - Age at outcome: } \\
\circ \text { Adults (19 years and older) }\end{array}$ \\
\hline
\end{tabular}

\footnotetext{
viii The Human Development classification was based on the Human Development Index (HDI) ranking from the year the study intervention occurred or data were collected (UN Development Program. HDI 1990-2017 HDRO calculations based on data from UNDESA (2017a), UNESCO Institute for Statistics (2018), United Nations Statistics Division (2018b), World Bank (2018b), Barro and Lee (2016) and IMF (2018). Available from: http://hdr.undp.org/en/data). If the study did not report the year in which the intervention occurred or data were collected, the HDI classification for the year of publication was applied. HDI values are available from 1980, and then from 1990 to present. If a study was conducted prior to 1990, the HDI classification from 1990 was applied. If a study was conducted in 2018 or 2019, the most current HDI classification was applied. When a country was not included in the HDI ranking, the current country classification from the World Bank was used instead (The World Bank. World Bank country and lending groups. Available from: https://datahelpdesk.worldbank.org/knowledgebase/articles/906519-world- country-and-lending-groups).
} 


$\begin{array}{lll}\text { Category Inclusion Criteria } & \text { Exclusion Criteria }\end{array}$

Health status

of study participants
- Studies that enroll participants who are healthy and/or at risk for chronic disease, including those with obesity

- Studies that enroll some participants diagnosed with a disease or with rickets.

- Studies that enroll infants born fullterm ( $\geq 37$ weeks and $0 / 7$ days gestational age)
- Studies that exclusively enroll participants diagnosed with a disease. (For this criterion, studies that exclusively enroll subjects with obesity were included.)

- Studies that exclusively enroll participants with rickets (i.e., studies that aim to treat participants who have already been diagnosed with the outcome of interest)

- Studies that exclusively enroll infants born preterm (gestational age $<37$ weeks and 0/7 days), infants with low birth weight $(<2500 \mathrm{~g})$, and/or infants born small for gestational age
- Vitamin D supplements (e.g., vitamin D drops)

- Mother's own milk

- Commercially prepared infant formula meeting FDA ${ }^{\mathrm{ix}}$ and/or Codex Alimentarius ${ }^{\mathrm{x}}$ international food standards (e.g., milk-based, soy, partially-hydrolyzed, extensivehydrolyzed, amino-acid based)
- Donor or banked milk

- Infant formulas that do not meet FDA and/or Codex Alimentarius standards

- Complementary foods/beverages

ix U.S. Food and Drug Administration. Version 19 December 2013. Internet: https://www.fda.gov/Food/GuidanceRegulation/GuidanceDocumentsRegulatoryInformation/InfantFormula/ucm13611 8.htm\#manufacture (accessed March 23, 2018).

${ }^{x}$ Food and Agriculture Organization of the United Nations. World Health Organization. Codex Alimentarius. International Food Standards. Standard for infant formula and formulas for special medical purposes intended for infants. Codex Stan 72-1981. 2007. 


\section{Electronic databases and search terms}

\section{PubMed}

- Provider: U.S. National Library of Medicine

- Date(s) Searched: January 13, 2020

- Date range searched: January 1, 2000 - January 13, 2020

- Search terms:

\#1 - vitamin d[Mesh] OR vitamin d [tiab] OR vitamin d3[tiab] OR cholecalciferol[tiab] OR ergocalciferol*[tiab]

\#2 - ("Bone Density"[Mesh] OR "bone density"[tiab] OR "Bone Development"[Mesh] OR "Bone Development"[tiab] OR osteogenesis[tiab] OR "Fractures, Bone"[Mesh] OR osteitis[tiab] OR bone turnover[tiab] OR bone loss[tiab] OR (bone[tiab] AND fracture*[tiab]) OR rickets [mesh] OR ricket* ${ }^{*}[$ tiab] OR bone mineral*[tiab] OR bone mass[tiab] OR bone health[tiab] OR bone demineral*[tiab]) OR ((bone[tiab] OR bones[tiab] OR "Bone and Bones"[Mesh] OR bone diseases[mh] OR bone development[Mesh]) AND (remodel*[tiab] OR form[tiab] OR osteolysis[tiab] OR ossification[tiab] OR resorption[tiab] OR accretion[tiab] OR bmc[tiab] OR bmd[tiab] OR "Biomarkers"[Mesh] OR biomarker*[tiab]))

\#3 - dietary supplements[Mesh] OR supplement*[tiab] OR drops[tiab] OR multivitamin*[tiab]

\#4 - \#1 AND \#2 AND \#3

\#5 - \#4 NOT ("Animals"[Mesh] NOT ("Animals"[Mesh] AND "Humans"[Mesh]))

\#6 - \#4 NOT (editorial[ptyp] OR comment[ptyp] OR news[ptyp] OR letter[ptyp] OR

review[ptyp] OR systematic review[ptyp] OR systematic review[ti] OR meta-analysis[ptyp] OR meta-analysis[ti] OR meta-analyses[ti] OR retracted publication[ptyp] OR retraction of publication[ptyp] OR retraction of publication[tiab] OR retraction notice[ti])

Publication Date Filters: Publication date from 2000/01/01 to 2020/01/13; English

\section{Cochrane Central Register of Controlled Trials (CENTRAL)}

- Provider: John Wiley \& Sons

- Date(s) Searched: January 13, 2020

- Date range searched: January 1, 2000- January 13, 2020

- Search terms:

\#1 - "vitamin d" OR [mh "vitamin d"[mj]] OR "vitamin d3" OR cholecalciferol OR ergocalciferol* \#2 - ([mh "Bone Density"[mj]] OR "bone density" OR [mh "Bone Development"[mj]] OR "Bone Development" OR osteogenesis OR [mh "Fractures, Bone"[mj]] OR [mh "Bone Diseases"[mj]] OR osteitis OR "bone turnover" OR "bone loss" OR (bone AND fracture*) OR ricket" OR "bone mineral" OR "bone mass" OR "bone health" OR "bone demineral") OR ((bone OR bones) NEAR/5 (remodel ${ }^{*}$ OR form* OR osteolysis OR ossification OR resorption OR accretion OR bmc OR bmd OR biomarker* OR [mh "Biological Markers"] )):ti,ab,kw

\#3 - [mh "dietary supplement"] OR supplement* OR drops OR multivitamin*

Filters: Publication Year from 2000 to 2020, Trials 


\section{Embase}

- Provider: Elsevier

- Date(s) Searched: January 13, 2020

- Date range searched: January 1, 2000 - January 13, 2020

- Search terms:

\#1 - 'vitamin d'/exp/mj OR 'vitamin d':ab,ti OR 'vitamin d3':ti,ab OR cholecalciferol:ab,ti OR ergocalciferol*:ab,ti

\#2 - (((bone OR bones) NEAR/6 (remodel* OR form* OR osteolysis OR ossification OR resorption OR accretion OR bmc OR bmd OR biomarker*)):ab,ti) OR ((bone NEAR/6 fracture*):ab,ti) OR 'bone density':ab,ti OR 'bone development':ab,ti OR osteogenesis:ab,ti OR osteitis:ab,ti OR 'bone turnover':ab,ti OR 'bone loss':ab,ti OR ricket*:ab,ti OR 'bone mineral ${ }^{*}: a b, t i$ OR 'bone mass':ab,ti OR 'bone health*':ab,ti OR 'bone demineral':ab,ti OR 'bone density'/exp/mj OR 'bone development'/exp/mj OR 'fracture'/exp/mj OR 'bone disease'/exp/mj

\#3 - 'dietary supplement'/exp OR supplement*:ti,ab OR drops:ti,ab OR multivitamin*:ti,ab OR 'multivitamin'/exp

\#4 - \#1 AND \#2 AND \#3

\#5 - \#4 AND ([article]/lim OR [article in press]/lim) AND [humans]/lim AND [english]/lim AND [2000-2020]/py NOT ([conference abstract]/lim OR [conference paper]/lim OR [editorial]/lim OR [erratum]/lim OR [letter]/lim OR [note]/lim OR [review]/lim OR [systematic review]/lim OR [meta analysis]/lim)

\section{Cumulative Index to Nursing and Allied Health Literature (CINAHL Plus)}

- Provider: Ebscohost

- Date(s) Searched: January 13, 2020

- Date range searched: January 1, 2000- January 13, 2020

- Search terms:

\#1 - "vitamin d" OR "vitamin d3" OR (MH "vitamin d") OR cholecalciferol OR ergocalciferol*

\#2 - (MH "Bone Density") OR "bone density" OR (MH "Bone Development") OR "Bone Development" OR osteogenesis OR (MH "Fractures, Bone") OR (MH "Bone Diseases") OR osteoporosis OR osteopenia OR osteitis OR "bone turnover" OR "bone loss" OR (bone AND fracture*) OR ricket" OR "bone mineral" OR "bone mass" OR "bone health" OR "bone demineral*" OR ((bone OR bones) N5 (remodel* OR form* OR osteolysis OR ossification OR resorption OR accretion OR bmc OR bmd OR biomarker*)) OR (bone* AND (MH "Biological Markers+")

\#3 - (MH "dietary supplements") OR supplement* OR drops OR multivitamin*

\#4 - \#1 AND \#2 AND \#3

\#5 - \#4 NOT (MH "Literature Review" OR MH "Meta Analysis" OR MH "Systematic Review" OR MH "News" OR MH "Retracted Publication" OR MH "Retraction of Publication )

Filters: Published Date: 20000101 to 20200113, English, Human 


\section{LITERATURE SEARCH AND SCREENING RESULTS}

The flow chart (Figure 2) below illustrates the literature search and screening results for articles examining the systematic review question. The results of the electronic database searches, after removal of duplicates, were screened independently by two NESR analysts using a step-wise process by reviewing titles, abstracts, and full-texts to determine which articles met the inclusion criteria. Refer to Table 5 for the rationale for exclusion for each excluded full-text article. A manual search was done to find articles that were not identified when searching the electronic databases; all manually identified articles are also screened to determine whether they met criteria for inclusion.

Figure 2: Flow chart of literature search and screening results

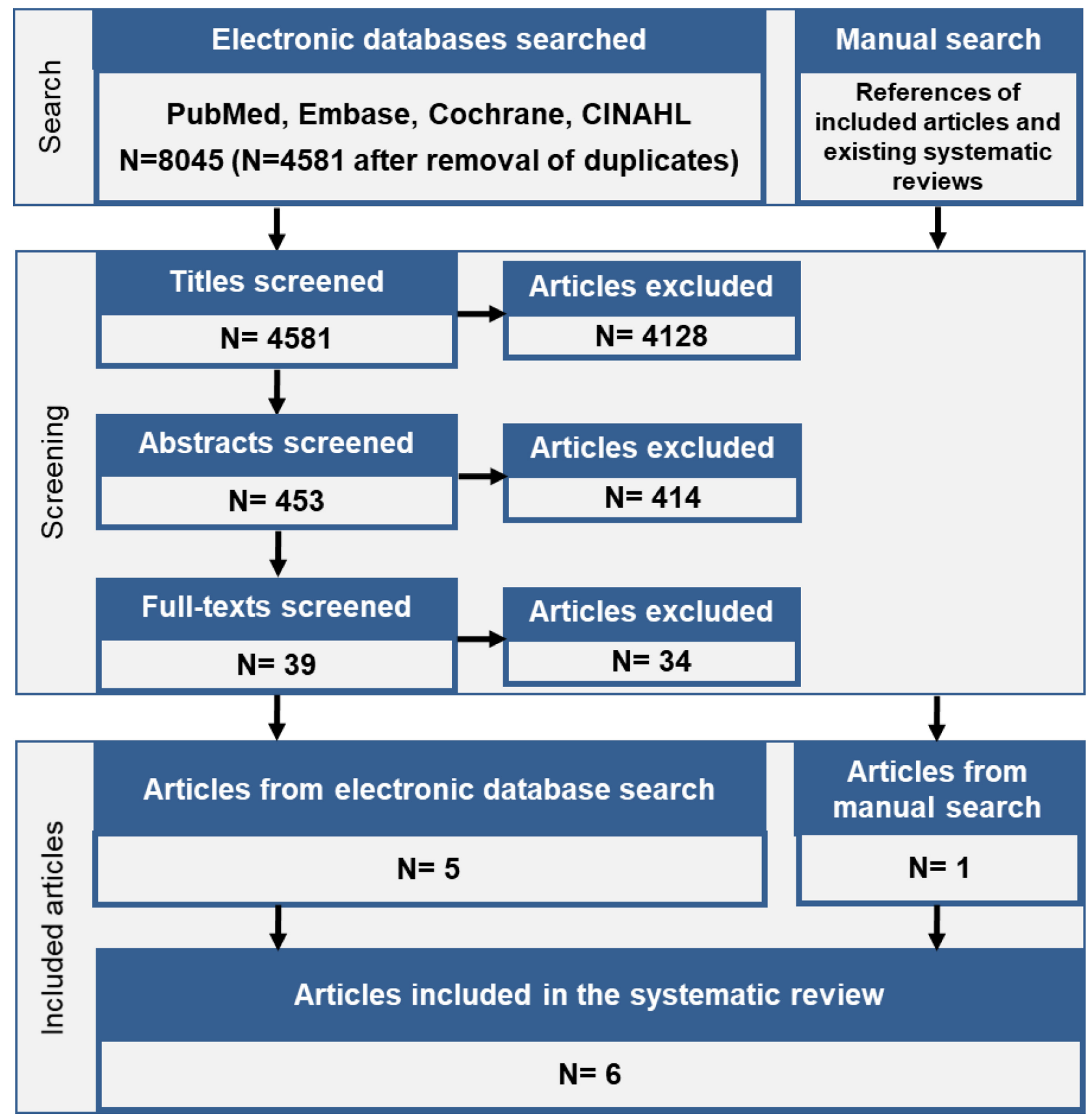




\section{Excluded articles}

\section{Table 5. Articles excluded after full text screening with rationale for exclusion}

The table below lists the articles excluded after full-text screening. At least one reason for exclusion is provided for each article, which may not reflect all possible reasons for exclusion. Information about articles excluded after title and abstract screening is available upon request.

\section{Full texts screened}

\section{Rationale for exclusion}

1 Abrams, S. A.,Hawthorne, K. M.,Rogers, S. P.,Hicks, P. D.,Carpenter, T. O. (2012). Effects of ethnicity and vitamin D supplementation on vitamin D status and changes in bone mineral content in infants BMC Pediatr, 12, 6

Intervention/exposure vs comparator

2 Bagnoli, F.,Casucci, M.,Toti, S.,Cecchi, S., Iurato, C.,Coriolani, G.,Tiezzi, M.,Vispi, L. (2013). Is vitamin D supplementation necessary in healthy full-term breastfed infants? A follow-up study of bone mineralization in healthy full-term infants with and without supplemental vitamin D Minerva Pediatr, 65(3), 253-60

3 Bly, E.,Huntington, J.,Harper, A. L.,Vincent, E. C. (2013). What is the best age to start vitamin D supplementation to prevent rickets in breastfed newborns? Journal of Family Practice, 62(12), 755+763

4 Czech-Kowalska, J.,Pludowski, P.,Dobrzanska, A.,Kryskiewicz, E.,Karczmarewicz, E.,Gruszfeld, D.,Pleskaczynska,

A., Golkowska, M. (2012). Impact of vitamin D supplementation on markers of bone mineral metabolism in term infants Bone, 51(4), 781-6

5 Gallo, S.,Rodd, C.,Vanstone, C.,Agellon, S.,L'Abbe, M.,Khamessan, A.,Weiler, H. (2011). Lumbar spine bone mineral density is enhanced in breast fed infants receiving 800 or $1200 \mathrm{IU}$ of vitamin d daily from 4 to 20 weeks of age Journal of bone and mineral research, 26

6 Hazell, T. J.,Gallo, S.,Vanstone, C. A.,Agellon, S.,Rodd, C.,Weiler, H. A. (2017). Vitamin D supplementation trial in infancy: body composition effects at 3 years of age in a prospective follow-up study from Montréal Pediatric obesity, 12(1), 38-47

7 Jackson, R. D.,LaCroix, A. Z.,Gass, M.,Wallace, R. B.,Robbins, J.,Lewis, C. E.,Bassford, T.,Beresford, S. A. A.,Black, H. R.,Blanchette, P.,Bonds, D. E.,Brunner, R. L.,Brzyski, R. G.,Caan, B.,Cauley, J. A.,Chlebowski, R. T.,Cummings, S. R.,Granek, I.,Hays, J.,Heiss, G. (2006). Calcium plus vitamin D supplementation and the risk of fractures [corrected] [published erratum appears in N ENGL J MED 2006 Mar 9;354(10):1102] New England Journal of Medicine, 354(7), 669-683

8 Jin, J. (2018). Vitamin D and Calcium Supplements for Preventing Fractures Jama, 319(15), 1630

9 Jorde, R.,Stunes, A. K.,Kubiak, J.,Joakimsen, R.,Grimnes, G.,Thorsby, P. M.,Syversen, U. (2019). Effects of vitamin D supplementation on bone turnover markers and other bone-related substances in subjects with vitamin D deficiency Bone, 124 7-13 
10 Jorde, R.,Strand Hutchinson, M.,Kjærgaard, M.,Sneve, M.,Grimnes, G. (2013). Supplementation with high doses of vitamin D to subjects without vitamin D deficiency may have negative effects: Pooled data from four intervention trials in Troms $\varnothing$ ISRN Endocrinology, 1(1)

11 Kim, M. J.,Na, B.,No, S. J.,Han, H. S.,Jeong, E. H.,Lee, W.,Han, Y.,Hyeun, T. (2010). Nutritional status of vitamin D and the effect of vitamin D supplementation in Korean breast-fed infants J Korean Med Sci, 25(1), 83-9

12 LeFevre, M. K. (2010). Rickets: A Preventable Growth Delay Journal of Pediatric Healthcare, 24(6), 408-412

13 McAllister, J. C.,Lane, A. T.,Buckingham, B. A. (2006). Vitamin D deficiency in the San Francisco Bay Area J Pediatr Endocrino Metab, 19(3), 205-8

14 Morandi, G.,Maines, E.,Piona, C.,Monti, E.,Sandri, M.,Gaudino, R.,Boner, A.,Antoniazzi, F. (2015). Significant association among growing pains, vitamin D supplementation, and bone mineral status: results from a pilot cohort study J Bone Miner Metab, 33(2), 201-6

15 Mutlu, G. Y.,Kusdal, Y.,Ozsu, E.,Cizmecioglu, F. M.,Hatun, S. (2011). Prevention of Vitamin D deficiency in infancy: daily 400 IU vitamin D is sufficient Int J Pediatr Endocrinol, 2011(1), 4

16 Ponnapakkam, T.,Bradford, E.,Gensure, R. (2010). Vitamin D supplementation in breastfed infants: results of a prospective trial in the southern United States Journal of bone and mineral research., 25, S232

17 Ponnapakkam, T.,Bradford, E.,Gensure, R. (2010). A treatment trial of vitamin d supplementation in breast-fed infants: Universal Duplicate supplementation is not necessary for rickets preventio in southern louisiana Clinical Pediatrics, 49(11), 1053-1060

18 Rangarajan, R.,Mondal, S., Thankachan, P.,Chakrabarti, R.,Kurpad, A. V. (2018). Assessing bone mineral changes in response to Participant age vitamin D supplementation using natural variability in stable isotopes of Calcium in Urine Sci Rep, 8(1), 16751

19 Rooze, S.,Mathieu, F.,Claus, W.,Yangzom, T.,Yangzom, D.,Goyens, P.,de Maertelaer, V. (2016). Effect of calcium and vitamin D on growth, rickets and Kashin-Beck disease in 0- to 5-year-old children in a rural area of central Tibet Trop Med Int Health, 21(6), 768-75

20 Savino, F.,Viola, S.,Tarasco, V.,Lupica, M. M.,Castagno, E.,Oggero, R.,Miniero, R. (2011). Bone mineral status in breast-fed infants: influence of vitamin D supplementation Eur J Clin Nutr, 65(3), 335-9

21 Sen, S.,Penfield-Cyr, A.,Hollis, B. W.,Wagner, C. L. (2017). Maternal Obesity, 25-Hydroxy Vitamin D Concentration, and Bone Density in Breastfeeding Dyads J Pediatr, 187, 147-152.e1

22 Shaikh, U.,Alpert, P. T. (2006). Nutritional rickets in Las Vegas, Nevada J Pediatr Endocrinol Metab, 19(3), 209-12

Intervention/exposure vs comparator

Outcome

Publication status

Intervention/exposure vs comparator

Participant age

Study design

Intervention/exposure vs comparator

Study design old infants at $63-66^{\circ} \mathrm{N}$ Nutrients, 6(3), 1182-1193

Study design 
24 Torjesen, I. (2018). Vitamin D supplements do not protect bone health, analysis finds Bmj, 363, k4223

25 Valkama, S., Holmlund-Suila, E., Enlund-Cerullo, M.,Rosendahl, J.,Hauta-Alus, H.,Helve, O.,Hytinantti, T.,Viljakainen,

Outcome

H.,Andersson, S.,Makitie, O. (2017). No Severe Hypercalcemia with Daily Vitamin D3 Supplementation of up to 30 microg during the First Year of Life Horm Res Paediatr, 88(2), 147-154

26 Valkama, S.,Holmlund-Suila, E.,Enlund-Cerullo, M.,Rosendahl, J.,Hauta-Alus, H.,Helve, O.,Hytinantti, T.,Viljakainen, H.,Andersson, S.,Mäkitie, O. (2017). No Severe Hypercalcemia with Daily Vitamin D3 Supplementation of up to $30 \mu \mathrm{g}$ during the First Year of Life Hormone research in paediatrics, 88(2), 147-154

27 van den Hooven, E. H.,Heppe, D. H.,Kiefte-de Jong, J. C.,Medina-Gomez, C.,Moll, H. A.,Hofman, A., Jaddoe, V. W.,Rivadeneira, F.,Franco, O. H. (2015). Infant dietary patterns and bone mass in childhood: the Generation R Study Osteoporos Int, 26(5), $1595-604$

Viljakainen, H. T.,Korhonen, T.,Hytinantti, T.,Laitinen, E. K.,Andersson, S.,Makitie, O.,Lamberg-Allardt, C. (2011). Maternal vitamin D status affects bone growth in early childhood--a prospective cohort study Osteoporos Int, 22(3), 883-91

Duplicate

28

9 Viljakainen, H. T.,Korhonen, T.,Hytinantti, T.,Laitinen, E. K. A.,Andersson, S.,Mäkitie, O.,Lamberg-Allardt, C. (2011). Maternal vitamin D status affects bone growth in early childhood-a prospective cohort study Osteoporosis International, 22(3), 883-891

30 Wicklow, B.,Gallo, S.,Majnemer, A.,Vanstone, C.,Comeau, K.,Jones, G.,L'Abbe, M.,Khamessan, A.,Sharma, A.,Weiler, H.,Rodd, C. (2016). Impact of Vitamin D Supplementation on Gross Motor Development of Healthy Term Infants: A Randomized DoseResponse Trial Phys Occup Ther Pediatr, 36(3), 330-42

31 (2012). Boning up on calcium and vitamin D. Do you need supplements to preserve your bone health? Johns Hopkins Med Lett Health After 50, 24(9), 1-2

32 (2006). Calcium and vitamin D supplements Med Lett Drugs Ther, 48(1240), 61

Intervention/exposure vs comparato

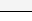

33 (2006). Calcium + vitamin D offers small bone improvements. But these supplements do not significantly reduce the risk of fractures Health News, 12(5), 6-7

34 (2011). How much vitamin D do you need? Johns Hopkins Med Lett Health After 50, 23(2), 7

Duplicate

Outcome

Publication status

Study design

Publication status

Publication status 